NBER WORKING PAPER SERIES

\title{
SUBSIDIES AND THE PERSISTENCE OF TECHNOLOGY ADOPTION: FIELD EXPERIMENTAL EVIDENCE FROM MOZAMBIQUE
}

\author{
Michael R. Carter \\ Rachid Laajaj \\ Dean Yang \\ Working Paper 20465 \\ http://www.nber.org/papers/w20465 \\ NATIONAL BUREAU OF ECONOMIC RESEARCH \\ 1050 Massachusetts Avenue \\ Cambridge, MA 02138 \\ September 2014
}

Aniceto Matias and Ines Vilela provided outstanding field management. We thank Luc Behaghel, Karen Macours, Craig McIntosh and seminar participants at the Barcelona GSE Summer Forum 2014, PACDEV 2014, MIEDC 2014, Paris School of Economics, UC Davis, UC San Diego and UC San Francisco for helpful feedback. This research was conducted in collaboration with the International Fertilizer Development Corporation (IFDC), and in particular we thank Alexander Fernando, Robert Groot, Erik Schmidt, and Marcel Vandenberg. Generous financial support was provided by the BASIS research program through the United States Agency for International Development grant number EDHA-00-06-0003-00. The views expressed herein are those of the authors and do not necessarily reflect the views of the National Bureau of Economic Research.

NBER working papers are circulated for discussion and comment purposes. They have not been peerreviewed or been subject to the review by the NBER Board of Directors that accompanies official NBER publications.

(C) 2014 by Michael R. Carter, Rachid Laajaj, and Dean Yang. All rights reserved. Short sections of text, not to exceed two paragraphs, may be quoted without explicit permission provided that full credit, including $(\mathcal{C}$ notice, is given to the source. 
Subsidies and the Persistence of Technology Adoption: Field Experimental Evidence from Mozambique

Michael R. Carter, Rachid Laajaj, and Dean Yang

NBER Working Paper No. 20465

September 2014

JEL No. O13,016,O33

\section{ABSTRACT}

We report the results of a randomized experiment testing impacts of subsidies for modern agricultural inputs in rural Mozambique. One-time provision of a voucher for fertilizer and improved seeds leads to substantial increases in fertilizer use, which persist through two subsequent agricultural seasons. Voucher receipt also leads to large, persistent increases in household agricultural production and market sales, per capita consumption, assets, durable good ownership, and housing improvements.

Consistent with learning models of the adoption decision, we find positive treatment effects on farmers' estimated returns to the input package. We also document positive cross-household treatment spillovers: one's own fertilizer use rises in the number of social network members receiving vouchers. Our findings are consistent with theoretical models predicting persistence of impacts of temporary technology adoption subsidies, in particular due to learning effects.

Michael R. Carter

Department of Agricultural and Resource Economics

University of California, Davis

One Shields Avenue

Davis, CA 95616

and NBER

mrcarter@ucdavis.edu

Rachid Laajaj

Campus Jourdan

48 Boulevard Jourdan

75014 Paris

France

rachid.laajaj@parisschoolofeconomics.eu
Dean Yang

University of Michigan

Department of Economics and

Gerald R. Ford School of Public Policy

735 S. State Street, Room 3316

Ann Arbor, MI 48109

and NBER

deanyang@umich.edu 


\section{Introduction}

Differences in technology are widely believed to explain cross-country differences in per capita GDP (Caselli and Coleman (2001), Comin and Hobijn (2004)). Given that the majority of the world's poor work in agriculture (IFAD (2011)), much attention has been focused on adoption of modern agricultural inputs. The substantial gains in agricultural productivity due to the Green Revolution involved introduction of improved seeds and modern fertilizers. ${ }^{1}$ In this context, Sub-Saharan Africa has proved to be an outlier: from 1960 to 2000, it experienced the smallest increase in agricultural yields across regions of the world (Evenson and Gollin (2003)). In 2009, fertilizer utilization in sub-Saharan Africa averaged only 13 kilograms per hectare; by contrast, in other developing countries the average was 94 kilograms per hectare. ${ }^{2}$

Motivated by this disparity, many sub-Saharan African countries have embarked on perhaps the most significant new development in agricultural policy over the past decade: large scale input subsidy programs aimed at raising the use of fertilizer and other modern inputs in agriculture. In ten African countries implementing input subsidy programs, program expenditures in 2011 amounted to $\$ 1.05$ billion, or 28.6 percent of public expenditures on agriculture (Jayne and Rashid (2013)). ${ }^{3}$

The rapid spread of fertilizer subsidies has occurred alongside active debate as to their desirability. Schultz (1964) argued that farmers are rational profit maximizers who will choose optimal fertilizer use levels, so subsidies introduce distortions and reduce social welfare. Other arguments against subsidies include negative environmental externalities (WorldBank (2007)) and regressive distribution schemes resulting from political influence and elite capture (Chibwana et al. (2010), Pan and Christiaensen (2011), Lunduka et al. (2013)). Advocates for subsidies point to market failures that would lead laissez-faire fertilizer use levels to be less than socially optimal. Motivated in part by concerns about such market failures, Sachs (2004) and Ellis (1992) have argued for fertilizer subsidies. In recent years, the World Bank has reversed previous decades' opposition to subsidies and now provides budget support for fertilizer subsidy programs

\footnotetext{
${ }^{1}$ Norman Borlaug famously called high-yielding seed varieties the "catalysts that ignited the Green Revolution", and chemical fertilizers "the fuel that has powered its forward thrust" (Borlaug 1972).

${ }^{2}$ FAO (Food and Agriculture Organization of the United Nations) statistics, accessible at http://faostat.fao.org/site/422/default.aspx\#ancor.

${ }^{3}$ Fertilizer subsidies are not limited to Africa, of course. Indian fertilizer subsidies are also substantial, amounting to 1.52 percent of GDP in 2008-09 (Sharma and Thaker (2009)).
} 
(Morris et al. (2007)). ${ }^{4}$ It is therefore important to shed light on the existence of any market failures in this context, so that rationales for input subsidies can be correctly evaluated.

We contribute to this debate on three fronts. First, we provide one of the first randomized controlled trials of the impact of an input subsidy program, and the first to measure impacts on a range of important household outcomes beyond fertilizer use itself. The only previous study using randomized methods is Duflo et al. (2011), who estimate impacts of fertilizer subsidies on fertilizer use alone (in rural Kenya). We show positive impacts of input subsidies (in Mozambique) on a range of outcomes beyond input use, including farm output, household consumption, assets, and housing quality.

Second, we find positive effects of input subsidies that persist up to two annual agricultural seasons beyond the season in which the subsidies were offered. This result contrasts with Duflo et al. (2011), who find no persistent impact of either "heavy" (50\%) subsidies for fertilizer or the "well-timed nudge" of offering free delivery at the time of the previous harvest. Both treatments raise fertilizer use in the season they are provided, but impacts are very close to zero and not statistically significantly different from zero in the next season.

Third, we provide the first field experimental evidence of agricultural technology adoption spillovers within a social network. ${ }^{5}$ Because the subsidy vouchers were randomly assigned, our study also generated random variation in the number of social network members (defined as those whom the respondent talked with at least moderately about agriculture in the previous season) who also received the input subsidy voucher. We find that one's own fertilizer use rises in the number of social network members receiving the voucher.

Our results provide support for some classes of theoretical models of agricultural households, and evidence against others, thereby sharpening the types of arguments that can (and cannot) be made in support of input subsidies. Our findings are consistent with models in which a one-time subsidy leads to persistent changes in technology adoption, such as models where subsidies create wealth effects that promote adoption, or that involve learning about the returns

\footnotetext{
${ }^{4}$ Duflo et al. (2011) provide experimental evidence from Kenya that farmers' behavioral biases leading to under-investment in fertilizer can be overcome more cost-effectively with well-timed small subsidies than large subsidies akin to those currently being implemented in sub-Saharan Africa.

${ }^{5}$ Previous randomized studies of social network spillovers have focused on adoption of health goods, and include Kremer and Miguel (2007), Dupas (2014), and Oster and Thornton (2012). Observational studies of agricultural technology adoption include Bandiera and Rasul (2006), Foster and Rosenzweig (1995), Conley and Udry (2010), and Munshi (2006).
} 
to fertilizer. We provide such a model in Section 2 of the paper.

A number of patterns in our results are consistent with the subsidies operating via the learning channel. First, voucher winning leads study participants to report higher estimated returns from use of the input package. In addition, the effect of having voucher winners in one's social network is similar in magnitude to the impact of winning a voucher oneself, and occurs only in years subsequent to the voucher distribution season (after the results of fertilizer use by voucher winners can be observed).

Our results are inconsistent with models where a one-time subsidy does not lead to persistent technology adoption. For example, a simple Ramsey-style model without capital market imperfections and an optimal steady-state level of input utilization would predict that a one-time subsidy would have only a temporary effect, and that utilization would rapidly return to the steady state. Our results also are contrary to the prediction of a behavioral model a la Duflo et al. (2011), in which partially naïve farmers who face stochastic temptation shocks systematically delay fertilizer purchases, so that some farmers wait too long and run out of liquidity right before planting time and thus have lower utilization than optimal. In such a setting, a one-time nudge or subsidy raises adoption only in the current season, and is not persistent. Similarly, arguments that fertilizers are simply not profitable at market prices because of soil characteristics (Marenya and Barrett (2009)) imply that once-off subsidies may have temporary, but not long-lasting, impacts.

Our work is related to existing research on market failures in technology adoption. Past work has shown that technology adoption is influenced by information imperfections, which lead to a need for learning about new technologies (Munshi (2006), Foster and Rosenzweig (1995), Bandiera and Rasul (2006), Conley and Udry (2010)); credit constraints (Miyata and Sawada (2007), Gine and Klonner (2005)); and insurance market failures (Dercon and Christiaensen (2007), Moser and Barrett (2006), Foster and Rosenzweig (2009)). ${ }^{6}$ Experimental research on the persistence of technology adoption in response to short-term subsidies for health goods is also related (Kremer and Miguel (2007), Dupas (2014), Tarozzi et al. (2014)).

In the rest of this paper, we first outline a simple theory that generates persistence of adoption in response to a one-time subsidy (Section 2). We then describe the study setting and experimental design in Section 3. Section 4

\footnotetext{
${ }^{6}$ Foster and Rosenzweig (2010) review the technology adoption literature in economics, including studies of fertilizer adoption.
} 
provides a description of the sample, balance tests, and attrition. In Section 5 we present the empirical results, and then conclude in Section 6 .

\section{A Model of the Impact of One-time Input Sub- sidies on Technology Adoption}

This section puts forward an economic model that allows us to explore the interaction between profitability, liquidity and information constraints on the use of fertilizer and improved seeds. The model provides a sharper understanding of when and how one-time input subsidies might spur sustained adoption of improved technologies and helps structure our subsequent empirical analysis.

The model assumes that households are risk averse, lack access to capital markets and are unable to borrow to finance the adoption of an improved agricultural technology. To cut down on verbiage, we will simply refer to this technology as fertilizer. Specifically, the model demonstrates:

1. Absent an input subsidy, a non-adoption equilibrium can emerge if initial living standards are low, especially if beliefs about the distribution of returns to fertilizer are downwardly biased or diffuse.

2. A one-time subsidy on the price of the new technology can move (some) otherwise non-adopting households to adopt the new technology.

3. If the subsidy-induced adoption does not have any learning effects, then technology adoption may persist after expiration of the subsidy through a pure wealth effect. This wealth effect is stochastic (dependent on realized returns to fertilizer) and sustained adoption under it may be fragile in the sense that poor outcomes can lead to subsequent reversion to the no fertilizer equilibrium.

4. Sustained adoption becomes more likely (and stable) if the wealth effect is accompanied by positive learning effect of one-time subsidies. Positive learning can occur through a reduction in pessimism about expected returns to fertilizers as well as through a reduction in the diffuseness or spread of beliefs about the distribution of fertilizer returns.

After laying out our core model assumptions, this section will first consider the impact of fertilizers on the short- and long-run adoption of fertilizers in the absence of learning. We will then open the model to learning and consider 
the additional insights and implications of temporary vouchers on sustained technology adoption. The Appendix explores learning about diffuseness.

\subsection{Technology and Subjective Beliefs}

We model the behavior of agricultural households that are risk averse and lack access to contracts for both insurance and credit. We assume that traditional production technology does not require purchased inputs and provides a fixed, non-stochastic output, $\bar{x}$. Households can choose to augment the traditional technology with a divisible improved technology that utilizes a purchased input $f$ (fertilizer) and produces output, $\bar{x}+y f$, where $y$ is the random return per unit fertilizer and we assume that it is distributed over the closed interval $\left[y_{-}, y^{+}\right]$, with probability distribution $\phi$ and with $E_{\phi}[y]=\bar{y} \cdot{ }^{7}$ Normalizing the price of the agricultural output to 1 and denoting the market price of fertilizer as $p_{f}$, note that absent subsidy, the technology will be is profitable in expectation if $\bar{y}>p_{f}$.

We justify this constant marginal impact of fertilizer via an "efficiency wage" theory of plant growth such that a given an amount of fertilizer is applied to an optimal area/number of plants, yielding a constant (expected) output increment per-unit fertilizer. ${ }^{8}$ Spreading this amount of fertilizer across a larger area will decrease returns. Note that this perspective is consistent with standard fertilizer practice which is to concentrate a limited amount of fertilizer in a small area, rather than spreading it out so that each plant gets only some tiny amount. Importantly, this production specification means that marginal returns to fertilizer are always finite, even at low levels of use..$^{9}$

As we are interested in the behavior of farm households that largely lack prior experience using the improved technology, we assume that farmers lack full information on the true distribution of $y$. In the simplest case, we assume that farmers correctly understand the dispersion in returns to the improved technology, but are systematically biased in their beliefs about the level of those

\footnotetext{
${ }^{7}$ Strictly speaking, this assumption applies only up to the point where the total amount of fertilizer exceeds the optimum amount for total farm size. We will ignore this eventual drop in returns to fertilizer as even the voucher program under study provides fertilizer well short of the optimum amount for the total cultivated area of households in our sample.

${ }^{8}$ Specifically we assume that plant yields are unresponsive at low levels of fertilizer or plant nutrition, and then have an increasing returns portion followed by a diminishing returns portion. As in the nutrition-based efficiency wage theory, this relationship will pin down a unique level of fertilizer that maximizes returns.

${ }^{9}$ Note that the same logic applies to improved seed as a small quantity of improved seeds will boost yields in the small area where they are planted, but cannot be ground up and spread out over the entire cultivated area for higher returns.
} 
returns. Specifically, we assume that individuals believe that returns to fertilizer are driven by a random variable $\tilde{y}=y-B$, where $B$ is the systematic bias in perceived returns. At time 0 , we denote the bias as $B_{0}$, and the subjective expected returns to fertilizer of $\tilde{y}$ given period 0 beliefs as $E_{0}(\tilde{y})=\overline{\tilde{y}}_{0}$. We define beliefs as pessimistic if $B_{0}>0$ and optimistic if $B_{0}<0$.

For the case in which priors are not diffuse, but are biased, we can write $\phi_{0}(\tilde{y})=\phi\left(y+B_{0}\right)$. Denote the corresponding subjective cumulative distribution function as $\Phi_{0}$. The appendix below generalizes this specification and allows uninformed farmers to have relatively diffuse prior beliefs about the distribution of returns to fertilizer.

\subsection{Technology Adoption in the Short and Medium Run without Learning}

In order to isolate the liquidity from the learning effects of voucher coupons, we first consider their impact assuming that no learning takes place. The next section will consider what happens when households update their priors about returns to fertilizers.

Consider a 3-period model of an agricultural household that produces and consumes the agricultural commodity. ${ }^{10}$ We assume that the household is offered a once-off input subsidy in in period 1 that reduces the cost of fertilizer from $p_{f}$ to $p_{f}-v$, where $v$ is the voucher value. After period 1 , the voucher expires and the price of fertilizer returns to its fixed market price of $p_{f}$. To explore the impact of this temporary fertilizer voucher subsidy, we consider the following model of an agricultural household that chooses how much to invest in first and second period savings $\left(s_{1}, s_{2}\right)$ and fertilizer $\left(f_{1}, f_{2}\right)$ in order to maximize expected utility given its prior subjective beliefs about the returns to fertilizer:

$$
\begin{gathered}
\max _{f_{1}, s_{1}, f_{2}, s_{2}} u\left(c_{1}\right)+\beta E_{0}\left[u\left(c_{2}\right)+\beta u\left(c_{3}\right)\right] \\
\text { subject to: } \\
c_{1} \leq z_{0}-\left(p_{f}-v\right) f_{1}-s_{1} \\
c_{2} \leq \bar{x}+y_{1} f_{1}-p_{f} f_{2}+r s_{1}-s_{2} \\
c_{3} \leq \bar{x}+y_{2} f_{2}+r s_{2} \\
f_{1}, s_{1}, f_{2}, s_{2} \geq 0
\end{gathered}
$$

\footnotetext{
${ }^{10}$ The assumption of only 3 periods, with households consuming all cash on hand in period 3 , is of course limiting, but it is sufficient to allow us to garner key insights on short and medium term technology adoption.
} 
where $\beta=(1+\delta)^{-1}$ is the per-period discount factor, $z_{0}$ is initial cash on hand for the household, $y_{1}$ and $y_{2}$ represent the realized returns to fertilizer in production periods 1 and 2, respectively, and $r$ is the fixed interest rate factor for first and second period savings. Given that returns to informal savings are low or even negative, we will assume that the households are impatient in the sense that $\beta r<1$. Under this assumption, households will only use financial savings to smooth consumption between periods, but not to build wealth.

\subsubsection{Second Period Problem}

We begin by examining second period choice conditional on realizations from the first year crop yield. Define second period cash-on-hand as $z_{2}=\bar{x}+y_{1} f_{1}+r s_{1}$. Note that second period cash on hand only depends on period 1 decisions and realizations. We can write the conditional second-period value function as:

$$
\begin{gathered}
V_{2}^{*}\left(z_{2}\right) \equiv \max _{f_{2}, s_{2}} u\left(c_{2}\right)+\beta E_{0}\left[u\left(c_{3}\right)\right] \\
\text { subject to }: \\
c_{2} \leq z_{2}-p_{f} f_{2}-s_{2} \\
c_{3} \leq \bar{x}+y_{2} f_{2}+s_{2} \\
f_{2}, s_{2} \geq 0
\end{gathered}
$$

The Kuhn-Tucker conditions for this problem are:

$$
\begin{array}{cl}
\frac{d V_{2}}{d f_{2}}=\beta E_{0}\left[y_{2} u_{3}^{\prime}\right]-u_{2}^{\prime} p_{f} \leq 0 ; & f_{2} \frac{d V_{2}}{d f_{2}}=0 \\
\frac{d V_{2}}{d s_{2}}=\beta r E_{0}\left[u_{3}^{\prime}\right]-u_{2}^{\prime} \leq 0 ; & s_{2} \frac{d V_{2}}{d s_{2}}=0
\end{array}
$$

As can be seen from these conditions, the key comparison determining fertilizer use is the comparison of the expected benefits $\left(E_{0}\left[y_{2} u_{3}^{\prime}\right]\right)$ to the shadow price of liquidity $\left(u_{2}^{\prime} p_{f}\right)$ and returns to savings, $r$.

Analysis of this problem simplifies when the first order conditions are evaluated at the corner solution value of $f_{2}=0$. At this value, third period cash on hand is non-stochastic, making $u_{3}^{\prime}$ independent of the random variable $y_{2}$. Evaluated at the corner solution $\left(f_{2}=0\right)$, the household will only set $f_{2}>0$ if the following expression is true:

$$
\frac{E_{0}\left[y_{2}\right]}{p_{f}}>\max \left[\frac{u_{2}^{\prime}}{\beta u_{3}^{\prime}}, r\right] .
$$


The first term on the right hand side says that expected returns under fertilizer must exceed the shadow price or opportunity cost of liquidity, while the second says that discounted expected returns to fertilizer must exceed returns to savings if any funds are to be invested in fertilizer. If this condition does not hold, then fertilizer adoption will never be sustained in the second period. That is, consumption will be smoothed using the available savings technology.

Assuming that expected returns to fertilizer exceed the returns to savings, $\frac{E_{0}\left[y_{2}\right]}{p_{f}}>r$, then we can define a critical level of cash on hand,

$$
\tilde{z}_{2}=\left\{z_{2} \mid \beta u_{3}^{\prime} E_{0}\left[y_{2}\right]=p_{f} u_{2}^{\prime}\left(z_{2}\right)\right\}
$$

such that the individual is just indifferent between adopting and not adopting the improved technology in period 2. At the corner solution $f_{2}, s_{2}=0$ increases in $z_{2}$ will only affect the shadow price of liquidity through $u_{2}^{\prime}$ and hence for values of values $z_{2}>\tilde{z}_{2}$, the individual will optimally adopt the new technology (i.e., set $f_{2}>0$ ), whereas no adoption will occur for lower values of $z_{2}$.

Using $\tilde{z}_{2}$, note that for any prior choices of $f_{1}$ and $s_{1}$ we can define the minimum period 1 fertilizer returns necessary to give cash on hand of $\tilde{z}$ and to sustain fertilizer adoption s:

$$
\underline{y}\left(f_{1}, s_{1}\right) \equiv \frac{\left(\tilde{z}_{2}-\bar{x}-r s_{1}\right)}{f_{1}} .
$$

Absent learning, $\mathrm{y}\left(f_{1}, s_{1}\right)$ is the minimum first period returns to fertilizer that must be realized in order or the household to sustain the adoption of the new technology in period 2. Note that $\mathrm{y}$ is decreasing in both of its arguments. A fertilizer subsidy that induces first period adoption of fertilizer thus creates a potential wealth effect that sustains fertilizer adoption in the second period by simply pushing net wealth or cash on hand above the minimum level $\tilde{z}_{2}$. In what follows, we will assume that $\tilde{z}>\bar{x}$. 


\subsubsection{First Period Problem}

Using the value function defined by 2 , we can now examine the first period problem as:

$$
\begin{gathered}
\max _{f_{1}, s_{1}} V_{1}\left(z_{0}\right) \equiv u\left(c_{1}\right)+\beta E_{0}\left[V_{2}^{*}\left(z_{2}\right)\right] \\
\text { subject to: } \\
c_{1} \leq z_{0}-\left(p_{f}-v\right) f_{1}-s_{1} \\
z_{2}=\bar{x}+y_{1} f_{1}+r s_{1} \\
f_{1}, s_{1} \geq 0
\end{gathered}
$$

In general form, we can write the first order conditions with respect to $f_{1}$ and $s_{1}$ as:

$$
\begin{gathered}
\beta \frac{\partial E_{0}\left[V_{2}^{*}\right]}{\partial f_{1}}-u_{1}^{\prime}\left(p_{f}-v\right) \leq 0 \\
\beta \frac{\partial E_{0}\left[V_{2}^{*}\right]}{\partial s_{1}}-u_{1}^{\prime} \leq 0
\end{gathered} .
$$

These conditions broadly mimic the conditions for the second period problem (3) except for two important differences. First the subsidy $v$ lowers the shadow price of a unit of fertilizer, making adoption of an interior solution with $f_{1}$ more likely. Second, the expected gains from fertilizer or savings are more complex.

To explore these expected gains, it is useful to break apart the second component of the maximand in (4) above into two pieces. Recalling that $\Phi_{0}$ is the cumulative distribution for prior subjective beliefs, we define $\Phi_{\mathrm{y}}=\Phi_{0}\left[\mathrm{y}\left(f_{1}, s_{1}\right)\right]=$ $\operatorname{Prob}\left(y_{1}>\mathrm{y}\left(f_{1}, s_{1}\right)\right)$ and rewrite the second component of the maximand (4) as:

$E_{0}\left[V_{2}^{*}\left(z_{2}\right)\right]=\left(1-\Phi_{\mathrm{y}}\right)\left\{E_{0}\left[V_{2}^{*}\left(z_{2}\right) \mid y_{1}<\mathrm{y}\left(f_{1}, s_{1}\right)\right]\right\}+\Phi_{\mathrm{y}}\left\{E_{0}\left[V_{2}^{*}\left(z_{2}\right) \mid y_{1}>\mathrm{y}\left(f_{1}, s_{1}\right)\right]\right\}$.

Denote the first term in curly brackets as $A$ and the second term in curly brackets as $B$. Note that $B \geq A$.

Using this expression, we can, for example, rewrite the first order condition with respect to $f_{1}$ as:

$$
\beta\left\{\left(1-\Phi_{\mathrm{y}}\right) A^{\prime}-\frac{\partial \Phi_{\mathrm{y}}}{\partial f_{1}} A\right\}+\beta\left\{\left(\Phi_{\mathbf{y}}\right) B^{\prime}+\frac{\partial \Phi_{\mathbf{y}}}{\partial f_{1}} B\right\}-u_{1}^{\prime}\left(p_{f}-v\right) \leq 0 .
$$

with a similar expression for the the derivative of $V_{1}$ with respect to $s_{1}$. Because it is the corner condition at no fertilizer use that will determine adoption of the new technology, we again evaluate the first order conditions at $f_{1}=0$. At this corner solution, note that $u_{2}^{\prime}$ is non-stochastic and that $\Phi_{\mathrm{y}}=0$, allowing us to 
rewrite conditions (5) as:

$$
\begin{gathered}
\beta\left\{u_{2}^{\prime} E_{0}\left[y_{1}\right]+\frac{d \Phi_{\mathrm{y}}}{d f_{1}}(B-A)\right\}-u_{1}^{\prime}\left(p_{f}-v\right) \leq 0 \\
\beta\left\{u_{2}^{\prime} r\right\}-u_{1}^{\prime} \leq 0
\end{gathered}
$$

where $\frac{d \Phi_{\mathrm{y}}}{d f_{1}}=\ldots \geq 0$. Note that with $B>A$, application of fertilizer not only has direct, short-term effect on second period well-being, but also an option value effect as it probabilistically opens the door to period 2 fertilizer investment and improved third period well-being.

As with the second period problem, there will be a critical minimum amount of cash-on-hand above which adoption occurs (if augmented expected returns exceed $r$ ). Note that this minimum level decreases with the magnitude of the subsidy and denote it as $\tilde{z}_{0}(v)$. Note also that pessimism about the returns to fertilizer (a larger value of $B_{0}$ which decreases $E_{0}\left[y_{1}\right]$ ) will make it less likely fertilizer will increase $\tilde{z}_{0}(v)$ and make it less likely that fertilizer will be adopted even with subsidy.

\subsubsection{Sustained Adoption and Disadoption}

We are now in a position to examine the economics of fertilizer adoption. Drawn for a given set of initial beliefs, Figure 1 partitions the space defined by initial cash on hand $\left(z_{0}\right)$ and stochastic first period fertilizer returns $\left(y_{1}\right)$ into three areas. The first area is for all households with initial cash on hand less than the minimum necessary to invest in fertilizer $\left(z_{0}<\tilde{z}_{0}(v)\right)$. If we assume that $\bar{x}<$ $\tilde{z}_{0}(v=0)$, then it is reasonable to assume that most households will not adopt fertilizer absent a subsidy. As the subsidy increases, the dashed vertical line in Figure 1 will shift to the left, crowding in more first period experimentation with fertilizer.

For those that adopt fertilizer in period 1, two outcomes are possible. If returns are high enough to push second period cash on hand above the critical level $z$, then adoption of the technology will be sustained. Given that returns to fertilizer are stochastic, note that those who sustain technology adoption will be only a subset of those who adopted it in period 1, with the second period adoption probability being an increasing function of first period fertilizer returns. The solid downward sloping curve in Figure 1 displays the values of $z_{0}$ and $y_{1}$ such that the household is just indifferent between disadoption and sustained second period adoption. Those above the curve will continue to use 
Figure 1: Fertilizer Adoption and Disadoption

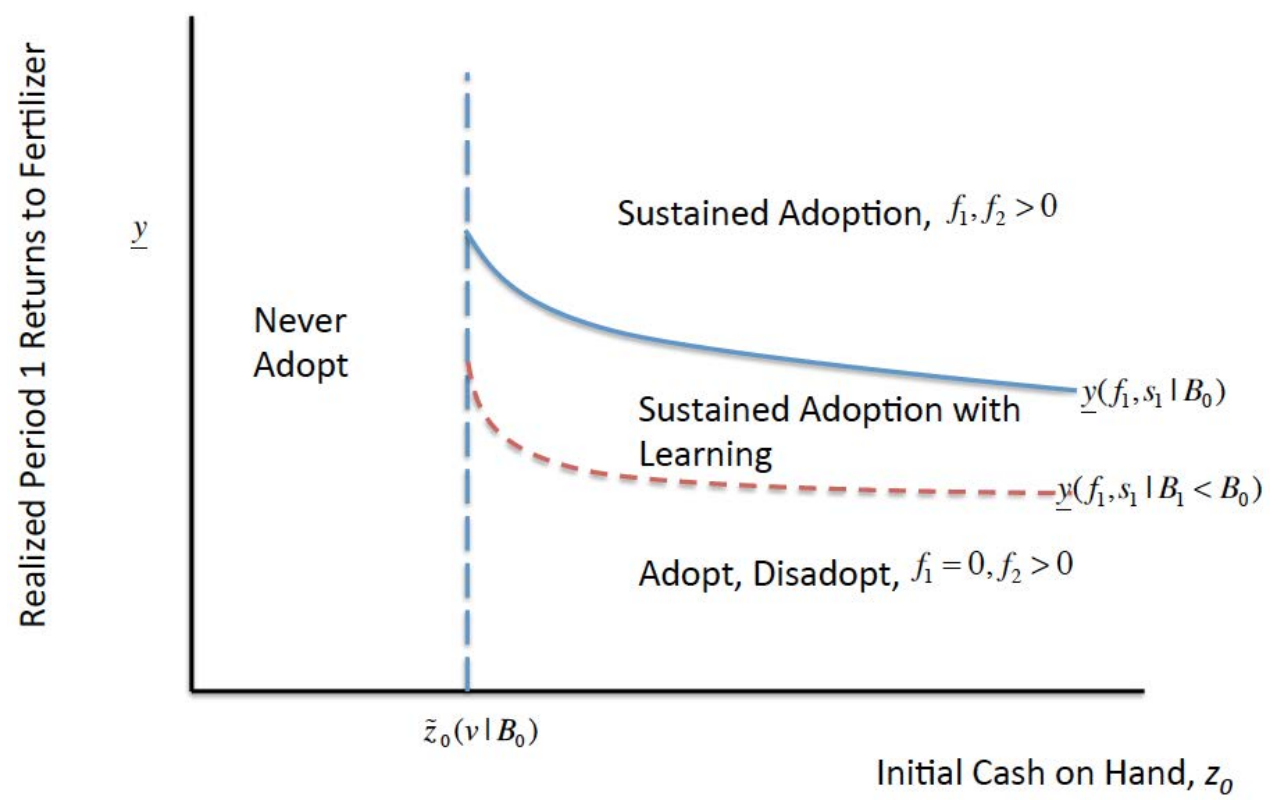

fertilizer in period 2.

For those with less buoyant first period returns $\left(y_{1}<\mathrm{y}\left(z_{0}\right)\right)$, disadoption will occur. Note that some of these households (with $0<y_{1}<\mathrm{y}$ ) may boost savings in order to smooth consumption between periods 2 and 3 . However, without more optimistic expectations about the returns to fertilizer, these households will not continue to adopt fertilizer beyond the subsidy period.

\subsection{Technology Adoption in the Presence of Learning}

The analysis so far has assumed that expected returns to fertilizer are unchanged by experience with the voucher coupons. However, individuals can learn from their own experience using fertilizers in period 1, as well as from the experience of others in their social network. Letting $y_{1}$ denote the returns to fertilizer obtained by the household in period 1, we define the information content of this information as $y_{1}^{*}=y_{1}-E_{0}(\tilde{y})$. Similarly, let $y_{1 n}$ be the yields that member $n$ of the farmer's social network obtained using fertilizer in period 1 and the information content as $y_{1 n}^{*}=y_{1 n}-E_{0}(\tilde{y})$. Assuming that the farmer has $N_{1}$ network members using fertilizer in period 1 , then we can define the information 
content of the signal that the farmer receives from the network as:

$$
y_{1 N}^{*}=\sum_{n=1}^{N}\left(\frac{y_{1 n}-E_{0}(\tilde{y})}{N_{1}}\right) .
$$

From a Bayesian learning perspective, the farmer will update the bias in prior beliefs about returns to fertilizer $\left(B_{0}\right)$ based on the strength of prior beliefs $\left(\sigma_{B_{0}}^{2}\right)$, the new information received $\left(y_{1}^{*}\right.$ and,$\left.y_{1 n}^{*}\right)$, and the variance or precision of that new information $\left(\sigma_{y_{1 n}^{*}}^{2}\right)$. Assembling these pieces, we posit a learning model in which $B_{1}=B_{0}+f\left(y_{1}^{*}, \sigma_{B_{0}}^{2}, y_{1 n}^{*}, \sigma_{y_{1 n}^{*}}^{2}\right)$. Foreshadowing the later empirical analysis in which we lack many of these specific measures, we note that the relative precision of the information received from the network depends on $N$, the number of network members experimenting with fertilizer. In simplest terms, we can rewrite the update equation as $B_{1}=B_{0}+f\left(d_{1}, N_{1}\right)$, where $d$ is a binary indicator of whether or not the farmer experimented with fertilizer in period 1.

How then does learning affect the use of fertilizer? To keep things (relatively) simple, we assume that learning is unanticipated, meaning that first period decisions are not affected by learning. However, realized fertilizer outcomes in excess of prior expectations will boost expected returns, lowering $\tilde{z}_{2}$ and $\mathrm{y}$, as shown by the dashed curve in Figure 1. Conversely, negative information shocks $\left(y_{1}^{*}, y_{1}^{n *}<0\right)$ will shift the curve in the opposite direction, making sustained adoption less likely. Note that from a longer term perspective, positive learning about the returns to fertilizer would be expected to inoculate future behavior against disadoption following a single bad realization that reduces household liquidity, implying greater stability in adoption.

One thing to notice here is that realized returns $\left(y_{1}\right)$ for the adopting household generates both a wealth effect and a learning effect. Without imposing further structure, an empirical finding that the farmer's own experimentation enhances future adoption would not cleanly identify whether such a persistent effect is the result of liquidity or learning effects, or some combination of the two. In contrast, experimentation by others in the farmer's social network would be expected to only influence farmer learning and not his or her liquidity. 


\section{Project Description}

\subsection{Agriculture in Mozambique and Input Subsidies in the Region}

Following its independence in 1975, Mozambique experienced 15 years of civil war. Despite impressive GDP growth since the end of the civil war, it remains one of the poorest countries in the world. In 2011, its Human Development Index was ranked 184th out of 187 countries rated. More than $75 \%$ of the Mozambican population works in small-scale agriculture, with little to no use of tractors, ploughs, fertilizer, pesticides, irrigation and other agro-inputs. The most common crops include maize, cassava, sweet potatoes, cotton, tobacco, sesame and groundnuts. The use of mineral fertilizer among smallholder farmers is primarily limited to cash crops and is scarce on cereal crops, leading to low yield, generally below one ton per hectare for maize production (compared to up to 8 tons per hectare in the most productive developing countries). The nascent input market is small and its network sparse. Between 1996 and 2003, agricultural production grew by an average of $6 \%$ per year, leading to a decrease in the rural poverty headcount, from $69 \%$ to $54 \%$ during the same period. However, Nankani et al. (2006) note that this growth mainly resulted from the expansion of area cultivated and labor due to the return of migrants, while technological improvements have been modest and yields almost stagnant.

In the 1970s and early 1980s in a majority of African countries, fertilizer was subsidized and sold through state-owned enterprises to address perceived under-provision of fertilizer by the market. Most public monopolies of agroinputs were eliminated during structural adjustment programs in the late 1980s. In the late 1990s, agro-input subsidies have re-emerged as what are now called "smart subsidies." Typically, vouchers are distributed to poor farmers, giving them access to an agro-input package provided by private sector input dealers at a subsidized price. Private sector dealers then trade the vouchers against the amount of the subsidy, at an intermediary bank or agency. This scheme has been claimed to offer the advantages of traditional fertilizer subsidy while stimulating rather than undermining the private sector, and targeting the poor more effectively. On the other hand, some have criticized failures in targeting the poor, and the low cost-effectiveness of the intervention (Minot and Benson, 2009). ${ }^{11}$

\footnotetext{
${ }^{11}$ For high-level reviews of input subsidy programs, also see Morris et al. (2007), Minot (2009), Druilhe and Barreiro-Hurle (2012), and Jayne and Rashid (2013).
} 


\subsection{Project Overview and Research Design}

The study that is the subject of this paper is nested within a larger study of the impact of input subsidies, formal savings programs, and the interaction of subsidy and savings programs. Localities in Manica province were selected to be part of the larger study on the basis of inclusion in the provincial input voucher program as well as access to a mobile banking program run by Banco Oportunidade de Mocambique (BOM, our implementation partner for the savings component of the project). To be accessible to the BOM savings program, which involved scheduled weekly visits of a truck-mounted bank branch, a village had to be within a certain distance of a paved road and within reasonable driving distance of BOM's regional branch in the city of Chimoio. These restrictions led to inclusion of 94 localities $^{12}$ in the larger study, across the districts of Barue, Manica, and Sussundenga.

Each of the selected 94 localities was then randomly assigned to either a "no savings" condition or to one of two savings treatment conditions ("basic savings" and "matched savings"), each with $1 / 3$ probability. The 32 localities (with 41 component villages) randomly selected to be in the "no savings" condition did not experience any savings treatment, and are the subject of this paper. ${ }^{13}$

Unlike many of its neighbors that launched nationwide input subsidy programs, ${ }^{14}$ Mozambique piloted a limited, two-year subsidy program funded by the European Union, implemented by Mozambique's Ministry of Agriculture, the Food and Agriculture Organization (FAO) and the International Fertilizer Development Center (IFDC). The limited scope of this program allowed the research team, in cooperation with the Ministry of Agriculture and IFDC, to design and implement a randomized controlled trial of the program. Over the 2009-10 and 2010-11 seasons, the pilot targeted 25,000 farmers nationally, of which 15,000 received a subsidy for maize production, and the remaining 10,000 received a subsidy for rice production. Among the recipients of the subsidy for maize production, 5,000 were in Manica province (in central Mozambique along

\footnotetext{
${ }^{12}$ The localities we use were defined by us for the purpose of this project, and do not completely coincide with official administrative areas. We sought to create "natural" groupings of households that had some connection to one another. In most cases our localities are equivalent to villages, but in some cases we grouped adjacent villages together into one locality, or divided large villages into multiple localities.

${ }^{13}$ In a separate companion paper, the remaining 62 localities randomly assigned to one of the savings treatments will be combined with the 32 "no savings" localities in analysis of the interaction between savings and input subsidy programs. Farmers in the 62 savings program localities were also included in lotteries for input vouchers.

${ }^{14}$ Such as, most notably, neighboring Malawi's national fertilizer subsidy scheme (Dorward and Chirwa (2011)).
} 
the Zimbabwean border), where the study was implemented.

Mozambique's input subsidy program provided beneficiary farmers with a voucher subsidizing the purchase of a technology package designed for a half hectare of improved maize production: $12.5 \mathrm{~kg}$ of improved seeds (either openpollinated variety or hybrid) and $100 \mathrm{~kg}$ of fertilizer (50 kg of urea and $50 \mathrm{~kg}$ of NPK 12-24-12). The market value of this package was MZN 3,163 (about USD 117), of which MZN 2,800 was for the fertilizer component, and MZN 363 was for the improved seed. Farmers were required to co-pay MZN 863 (USD 32), or $27.2 \%$ of the total value of the package. ${ }^{15}$

Lists of eligible farmers were created jointly by government agricultural extension officers, local leaders, and agro-input retailers. Individuals were deemed eligible for a voucher coupon if they met the following program criteria: 1) farming between 0.5 hectare and 5 hectares of maize; 2) being a "progressive farmer," defined as a producer interested in modernization of their production methods and commercial farming; 3) having access to agricultural extension and to input and output markets; and 4) being able and willing to pay for the remaining $27 \%$ of the package cost. Only one person per household was allowed to register. Participants were informed that a lottery would be held and only half of those on the list would win a voucher. Vouchers were then randomly assigned to $50 \%$ of the households on the list in each village. ${ }^{16}$ Randomization was conducted by the research team on the computer of one of the PIs, and the list of voucher winners was provided to agricultural extension officers. Extension officers were responsible for actual voucher distribution to beneficiaries.

The annual agricultural season in Mozambique runs from November (when planting starts) through harvest the following June. The timing of the intervention and various surveys was largely determined by this annual cycle. The schedule of specific project activities was as follows:

- Sept-Dec 2010: Random assignment and distribution of vouchers

- April 2011: Survey to establish voucher use and agricultural outcomes in prior season

- September 2011: First follow-up survey

- September 2012: Second follow-up survey

\footnotetext{
${ }^{15}$ At the time of the study, one US dollar (USD) was worth roughly 27 Mozambican meticals (MZN).

${ }^{16}$ In other words, villages served as stratification cells.
} 
- August 2013: Third follow-up survey

\section{Sample, balance tests, and attrition}

Our sample for analysis in this paper consists of 514 study participants and their households in 41 villages (in 32 localities or groupings of villages). In each one of these villages, $50 \%$ of study participants were randomly selected to receive an input voucher.

Table 1 provides summary statistics on the study households, and tests for balance on these variables across study participants in the treatment (voucher winners) and control (voucher losers) groups. Sample household heads are $85 \%$ male and $78 \%$ are literate. By comparison, in rural Manica province, only $66 \%$ of household heads are male and $45 \%$ are literate. ${ }^{17}$ This is perhaps not a surprise given the initial intention of targeting "progressive" farmers. Study households own an average 10.3 hectares of land (the sample median is 5 hectares). $11 \%$ of households have electricity at home, and $19 \%$ used fertilizer on at least one of their maize fields during the 2009-2010 season, prior to this study. While better off than some in the province, the study population is nonetheless dominated by poor small-scale farmers with limited experience with modern agriculture.

Due to uncertainties in the timing of voucher distribution and delays in the creation of the list of study participants, it was not feasible to conduct a baseline survey prior to the voucher lottery. Instead, we implemented a survey after the distribution of vouchers, but asked retrospective questions on respondents' pre-lottery agricultural outcomes and behaviors. We check balance between treatment and control groups for variables that are not expected to vary in the short run (for example education of the household head), or variables related to the 2009-10 agricultural season (the season prior to our study.) The rightmost columns of Table 1 present the means of these variables in the control and treatment groups separately, and the p-values of F-tests of equality of these means. The sample is balanced on all of these variables.

It is important to consider attrition from the study, and consider whether such attrition could lead to biased treatment effect estimates. We attempted to survey everyone in the initial sample at each subsequent survey round (in other words, attrition was not cumulative), so all attrition rates reported are

\footnotetext{
${ }^{17}$ The Manica data used for comparison is from the 2007 "Terceiro Recenseamento Geral da População e Habitação", provided by Mozambique's National Institute of Statistics, accessible online at http://www.ine.gov.mz/home_page/censo2007.
} 
vis-à-vis that initial sample. Attrition is $8.6 \%$ in the first (2011) follow-up survey, $10.0 \%$ in the second (2012) round, and $7.6 \%$ in the final (2013) round. In Online Appendix Table 1, we examine whether attrition is related to treatment assignment. The regressions of the table regress the dummy for treatment (winning the voucher lottery) on attrition, controlling for village fixed effects. In no case is attrition large or statistically significantly different from zero. Attrition bias is therefore not likely to be a concern in this context.

\section{Empirical results}

Random treatment assignment allows us to estimate the causal impact of eligibility for fertilizer subsidy vouchers. Treatment effect estimates for outcome $Y_{i v}$ for study participant $i$ in village $v$ are obtained via estimation of the following regression equation:

$$
Y_{i v}=\alpha+\beta Z_{i v}+\theta_{v}+\epsilon_{i v}
$$

Because use of the voucher is potentially endogenous to farmer characteristics, we focus on the impact of exogenously-determined treatment status. Our estimates will be intent to treat (ITT) effects of voucher receipt on the outcomes of interest. $Z_{i v}$ is an indicator variable taking the value of 1 if the individual is in the treatment group (won the lottery for the fertilizer subsidy voucher), and 0 otherwise. The parameter of interest is the coefficient $\beta$ on this treatment indicator, the estimate of the treatment effect of subsidy voucher receipt. The regression variables do not have time subscripts: we run this regression separately for outcomes in each of the three annual post-treatment follow-up surveys that we implemented. This allows examination of changes in the treatment effect over time.

$\theta_{v}$ are stratification cell fixed effects representing the village of the study participant (recall that treatment was randomly assigned within village, so each village contains both treated and control study participants.) We report $\mathrm{Hu}-$ ber/White heteroskedasticity-consistent standard errors.

Outliers may have undue influence on the treatment effect estimates for certain variables (such as fertilizer utilization in kilograms, or production in kilograms or money units). We take two approaches to reduce the influence of outliers. First, we take the inverse hyperbolic sine transformation (IHST) of 
dependent variables. ${ }^{18}$ Second, when expressing certain variables in levels, we truncate the variable at the 99 th percentile (we replace values above the 99 th percentile with the 99 th percentile). The results tables will always show both IHST and levels (with 99th percentile truncation) specifications.

Outcome variables of particular interest in this study include those that have substantial noise and relatively low autocorrelation, such as farm inputs and outputs. In this case, one can achieve increases in statistical power by taking multiple post-treatment outcome measures and estimating treatment effects on the average of post-treatment outcomes across multiple periods (McKenzie (2012)). We therefore also show impacts on average outcomes across the 2012 and 2013 seasons, which follow the "treated" 2011 season for which the input vouchers were distributed.

\subsection{Voucher Take-up}

We first examine take-up of the subsidy voucher. ${ }^{19}$ An important first point to note is that there was non-compliance in both the treatment group and in the control group: in the treatment group, not all voucher winners used the voucher, and some farmers in the control group received the voucher.

Our study took place in the context of a government fertilizer voucher program, so distribution of vouchers to study participants was the responsibility of government agricultural extension agents (not our research staff). Under the supervision of the research team, extension agents held a voucher distribution meeting in each village to which all voucher winners in that village were invited. By itself, the requirement to co-finance the input package should be expected to lead nontrivial fractions of winners to choose not to take the voucher. In practice, $48.7 \%$ of voucher winners actually showed up and received their voucher. ${ }^{20}$

Contrary to the study design that was agreed upon with the Manica provincial government, some control group respondents (voucher lottery losers) also ended up receiving vouchers. This resulted from a mismatch in objectives between provincial government leadership and extension agents on the ground who

\footnotetext{
${ }^{18}$ The inverse hyperbolic sine transformation (IHST) of $x$ is $\log \left(x+\left(x^{2}+1\right)^{\frac{1}{2}}\right)$. When dependent variables are expressed in IHST, treatment effects can be interpreted as elasticities (as with the $\log$ transformation), but unlike the log transformation it is defined at zero. Burbidge et al. (1988) recommend the use of the IHST rather than the log transformation.

${ }^{19}$ Voucher take-up and voucher use variables are reported by study participants in the first survey (April 2011).

${ }^{20}$ No voucher winners were denied vouchers if they wanted them, so all voucher non-receipt resulted from farmers choosing not to take the vouchers.
} 
were actually distributing vouchers. Extension agents were each given a certain number of vouchers to distribute in the months leading up to the December 2010 planting period (including areas separate from the study villages.) The fact that take-up of the vouchers was less than $100 \%$ in the study villages meant that the unused vouchers were expected (by the national government and donor agencies funding the program) to be distributed to other farmers. Our research team emphasized that these unused vouchers should only be distributed outside the study villages. We were not entirely successful in ensuring this, however, since it was much less effort for extension agents to simply redistribute unused vouchers in the study villages (extension agents did not need to incur time and other costs of travel to other villages.) In the end, $12.9 \%$ of study participants in the control group received vouchers.

It is clear, therefore, that our intervention should be considered an "encouragement design." Random assignment led to higher voucher receipt in the treatment group than in the control group. Table 2, column 1 displays results from a regression of an indicator for voucher receipt on the treatment indicator (and village fixed effects). ${ }^{21}$ The coefficient on treatment is positive and statistically significant at the $1 \%$ level, indicating that the treatment led to an increase of the rate of voucher receipt from $14 \%$ to $51 \%$.

Voucher receipt did not guarantee actual use of the voucher. Some voucher recipients chose not to bear the financial cost of the input package co-payment, and the transport cost to and from the input supplier. The impact of assignment to the treatment group on actual use of the voucher is therefore lower, in percentage points, than the impact on voucher receipt. Table 2, column 2 presents results from a regression of an indicator of voucher use (actual purchase of the subsidized input package) on the treatment indicator. The coefficient on treatment is positive and statistically significantly different from zero at the $1 \%$ level, indicating a 29 percentage point increase in voucher use (more than tripling the control group rate of $12 \%$.)

Non-compliance with treatment assignment reduces our statistical power to detect treatment effects on subsequent outcomes, but otherwise should not threaten the internal validity of the results. While we would have hoped to have seen greater compliance, our setting may be relatively representative of the actual implementation of voucher programs in many field settings, particularly

\footnotetext{
${ }^{21}$ The dependent variable is equal to one if the household received at least one voucher. Out of the 154 households who received at least one voucher, 146 received exactly one voucher, and 8 received two vouchers.
} 
when programs are implemented in collaboration with governments.

\subsection{Treatment effect estimates}

In this section, we trace the causal chain of voucher impacts, beginning with impacts on input use, followed by agricultural production and sales, and indicators of household well-being. We then assess the change in learning about expected returns to better understand underlying mechanisms.

\subsubsection{Input utilization}

The vouchers provided a subsidy for use of fertilizer and improved seeds, so we first examine treatment effects on these outcomes. Table 3 presents estimates of treatment effects ( $\beta$ from equation 6 ). Panel A presents regressions where dependent variables are expressed in inverse hyperbolic sine transformation (IHST), while in Panel B dependent variables are in levels (truncated at the 99th percentile.) In each panel, we present treatment effects separately in three post-treatment seasons: 2011 (the season for which vouchers were provided), as well as 2012 and 2013 (for which no vouchers were provided). We also show treatment effects on the average of the 2012 and 2013 dependent variables, which improves power by averaging out noise (McKenzie (2012).) This table format will be followed in the next two results tables as well.

The treatment had a clear positive impact on fertilizer use in the season 2010-11, for which the vouchers were provided. In both the IHST and levels specifications, the treatment had a positive and statistically significant impact on fertilizer use on maize in kilograms, fertilizer use on maize in $\mathrm{kg}$ per hectare, and total fertilizer used on all crops (in $\mathrm{kg}$ and in Mozambican meticals or MZN). There is no large or statistically significant impact on fertilizer use on crops other than maize in that year. There is also a positive impact on use of improved seeds (in $\mathrm{kg}$, and in $\mathrm{kg}$ per hectare), which is statistically significant in the IHST specification.

The magnitude of the treatment effect on fertilizer use is consistent with voucher take-up rates and the size of the input package. The treatment led to a 29 percentage point increase in voucher use (Table 2, col. 2), and the input package included $100 \mathrm{~kg}$ of fertilizer. If farmers taking up the package used the entire package and did not substitute for fertilizer they would have used anyway, the treatment effect on take-up would imply a treatment effect on fertilizer use amounting to $29 \mathrm{~kg}$. This is very similar to the estimated treatment effect in 
Table 3, Panel B, column 4: $22.7 \mathrm{~kg}$ (significant at the 5\% level). This result raises no substantial concerns that the subsidy voucher crowded out private demand for fertilizer on the part of study participants, which has been found in other contexts (Jayne et al. (2013).)

Impacts on fertilizer use persist in the subsequent 2012 and 2013 seasons. The impact on average fertilizer use across 2012 and 2013 in total across all crops (column 4) is statistically significant at the $1 \%$ level in both the IHST and levels specifications, with a coefficient magnitude (19.13 kg in the levels regression) that is not much smaller than the impact in $2011(22.72 \mathrm{~kg})$. The same patterns and significance levels hold when the dependent variable is the money value of total fertilizer used on all crops (column 5). The treatment effects indicate fertilizer use on crops other than maize: impacts on fertilizer use on both maize and non-maize crops (columns 1 and 3) are statistically significant in the IHST specifications (and positive but only marginally significant in the levels regressions). ${ }^{22}$

By contrast, impacts on improved seed use do not persist into 2012-13: treatment effects in those periods are small and are not statistically significantly different from zero. One point of note is that in the season prior to the intervention, $22 \%$ of the households were using fertilizer for maize cultivation compared to $53 \%$ for improved seeds. Given relatively high usage of improved seeds prior to the intervention, it may be that improved seed utilization was already near optimal levels, while fertilizer use was not.

\subsubsection{Farm production and market sales}

Given the treatment effects on fertilizer use, it is natural to next examine impacts on crop production and market sales. We do so in Table 4.

The treatment has positive impacts on maize production and yield (columns 1 and 2) in the subsidy year, 2011. Impacts on yield are statistically significantly different from zero at the $5 \%$ level in the IHST and levels specifications. There is no evidence of impacts in that year on production of other crops (column 3),

\footnotetext{
${ }^{22}$ Treatment effects on fertilizer use in the 2012 and 2013 seasons do not appear to be simply due to respondents saving some fertilizer from their subsidized input packages (that were intended to be used in 2011) for use in 2012 or 2013. Respondents were surveyed in 2011 and, if they had redeemed the subsidy voucher for inputs, were asked "What did your household do with the fertilizer purchased with the voucher?" Only $2.8 \%$ reported they had not used the voucher yet. $88.7 \%$ said they had already used it for agricultural production. The remainder said they had sold the voucher $(1.4 \%)$, gave some other response $(1.4 \%)$, or did not respond to the question $(5.6 \%)$.
} 
the total value of crop production (column 4), or on sales of maize or all crops combined (columns 5 and 6).

Positive treatment effects on maize yield persist into the 2012-13 postsubsidy seasons, and are accompanied by positive impacts on production of other crops and on total production. Regressions for the average of 2012-13 outcomes reveal positive treatment effects on other crop production and total crop production that are significant at conventional levels in both the IHST and levels specifications. The positive effect on other crop production is likely related to the increase in fertilizer use on other crops that occurs post-subsidy.

The economic magnitude of the effect on total crop production is substantial. On average across 2012-13, the treatment leads to MZN 3,906 higher crop production (significant at the $5 \%$ level), a $21.6 \%$ increase over the level in the control group. This is consistent with the 0.16 effect in the IHST specification and exceeds the market value of the package.

One of the objectives of the Mozambican subsidy program was the transformation of subsistence farmers into commercial farmers who sell their output in markets. The last two columns of Table 4 therefore examine treatment effects on market sales of maize and of all crops combined. There is no large or statistically significant effect in the subsidy year, but positive effects emerge subsequently. On average across the 2012-13 seasons, the treatment leads to higher market sales of both maize and all crops. These effects are statistically significant at the $5 \%$ level in the IHST specification for both outcomes.

\subsubsection{Consumption, savings, assets, and housing quality}

We now turn to treatment effects on consumption, savings, assets, and housing. Regression results are in Table 5.

There are no impacts on any of these outcomes in the subsidy year, 2011. Point estimates are typically small in magnitude, and none are statistically significantly different from zero at conventional levels.

Positive impacts emerge in the following two post-subsidy years. Again, we focus the discussion on impacts on the average of the 2012 and 2013 outcome variables. The treatment effect on per capita daily consumption in the household (column 1) is positive and statistically significant at the $5 \%$ level in both the IHST and levels specifications. ${ }^{23}$ The impact amounts to MZN 10.59 per day,

\footnotetext{
${ }^{23}$ In results not shown, we find no large or statistically significant impact of the treatments on the number of household members, in total as well as in various age subcategories.
} 
$14.7 \%$ increase over the mean in the control group. One might take this as perhaps the best overall summary result indicating that the treatment led to an improvement in household well-being.

The remaining columns of the table examine impacts on various types of assets. There are positive effects on all types of assets in columns 2-5, which are substantial in magnitude and statistically significantly different from zero in IHST specifications in the case of total savings, livestock, food stocks, and total savings and assets (column 6). Results in levels specifications are also positive and large in magnitude, but are less precise, so only the results for total savings and food stocks are statistically significant (both of these at the $1 \%$ level).

Table 6 presents impacts of the treatment on housing improvements (which were not included in total assets and savings in Table 5). The first dependent variable is a dummy that is equal to one if the respondent reported undertaking any housing improvement (across the specific types in the table). There is no impact in the first year, but on average over the subsequent two years there is a 4 percentage point increase in the likelihood of making any housing improvement that is statistically significant at the $5 \%$ level, providing additional evidence of long term improvement in the living conditions of the beneficiaries. The remaining columns of the table reveal that the specific areas of housing improvement are in walls and floors. The fact that most improvements occur in the year 2013 is consistent with the need for a period of savings before making this lump sum investment.

\subsection{Learning effects}

Our theoretical model makes clear that a temporary subsidy could have persistent effects on technology adoption either via a wealth channel, or via learning about the returns to the technology. To shed light on whether a learning channel is operative, we asked farmers in all three survey rounds the following questions about perceived returns to fertilizer: "In the first field where your household planted maize this year, if you use improved seed and fertilizer, what is the total production that is expected in: a) an average year, b) a very good year, and c) a very bad year?". Respondents were told to assume the use of $100 \mathrm{~kg}$ of urea, $100 \mathrm{~kg}$ of NPK fertilizer, and $25 \mathrm{~kg}$ of improved seeds per hectare. Respondents also gave estimates assuming that no improved inputs had been used, and were asked to indicate how many years out of ten they expected to be average, very good and very bad years. These probability elicitations allow us to calculate 
farmers' unconditional expected returns to improved seeds and fertilizers.

Table 7 presents estimated impacts of the treatment on expected returns without the input package (column 1), with the input package (column 2) and the difference between the two (column 3). The latter can be interpreted as the expected returns to the input package. The coefficient on treatment is positive in each regression, and is statistically significantly different from zero in the IHST specifications for expected yield with fertilizer and for the returns to the input package, in 2011, 2012, and on average over the 2012-13 seasons. Interestingly, treatment effects on all outcomes in the 2013 season are consistently smaller in magnitude and none are statistically signicantly different from zero. This may reflect knowledge spillovers over time to the control group, so that differences vis-a-vis the treatment group are attenuated.

These findings that the treatment raised perceived returns to the input package are consistent with the existence of a learning channel, as outlined in the theoretical section.

\subsection{Spillovers in the social network}

Our theoretical model allows the subsidy to affect technology adoption via learning about the returns to the new technology, not only from one's own experience but also from the experience of others in one's social network. Examination of social network effects is also of interest because experimentation by others in one's social network would be expected to only influence farmer learning and not his or her liquidity. Effects stemming from experimentation in the social network are therefore more likely to be due to learning than wealth effects.

Our study design involved randomizing treatment assignment within villages, so fertilizer adoption of study participants could be affected not only by their own treatment status, but also by the extent of treatment (voucher winning) in their social networks. To analyze effects of treatment within the social

network, we estimate the causal effect of the number of social network members winning vouchers in the lottery. This analysis relies on two features of our study.

First, we have data on social network links prior to treatment, which we collected ourselves in a manner analogous to Conley and Udry's (2010) elicitation of "information links". Study participants were presented with the full list of other study participants in the same village, and asked which of these they talked to about agriculture in the season prior to the study (2009-2010), and if so whether they did so "a bit", "moderately", or "a lot". For each study 
participant, others whom they indicated as having talked to about agriculture "moderately" or "a lot" are considered part of the participant's social network. ${ }^{24}$ Note that, because we are interested in understanding spillovers of our randomized treatment within the social network, this elicitation only captures social network links among study participants in the village, not the full set of social network links (which would include study non-participants). Each respondent was asked about their links with 11.5 other study partipants on average. Crucially for this analysis, respondents report quite substantial variation in social network links with other study participants (in other words, study participants do not have identical social networks). The distribution of number of social network links is given in Table $8 \mathrm{~A}$. The median number of social network links is two. $30.0 \%$ of respondents said they had no social network links with other study participants. $16.1 \%$ said they had one link, $12.6 \%$ had two, $7.4 \%$ had three, $8.6 \%$ had four, and $25.3 \%$ had five or more. ${ }^{25}$

Second, we take advantage of the fact that randomization of the input subsidy voucher also generates random variation in the number of voucher winners within a respondent's social network. Table $8 \mathrm{~B}$ presents the distribution of number of voucher winners in a respondent's social network. The median number of voucher winners in the social network is one. $44.0 \%$ of respondents have zero voucher winners in their social network. $18.3 \%$ have one, $15.0 \%$ have two, $8.2 \%$ have three, $5.8 \%$ have four, and $8.8 \%$ have five or more. Among the 360 individuals with at least one study participant in their social network, the ratio of number of voucher winners in the social network to number of study participants in one's social network has a mean of 0.485 , very close to the 0.5 ratio that would be expected given the one-half probability of voucher winning.

We estimate impacts of voucher winning in the social network on fertilizer use $\left(Y_{i v}\right)$ for study participant $i$ in village $v$, via the following modified version of the ITT regression equation 6 :

$$
Y_{i v}=\alpha+\beta Z_{i v}+\sum_{k=1}^{5+} \gamma_{k} W_{i v}^{k}+\sum_{k=1}^{5+} \lambda_{k} S_{i v}^{k}+\theta_{v}+\epsilon_{i v}
$$

As in equation $6, Z_{i v}$ is the individual treatment indicator, and the regression includes village fixed effects. In addition, this regression includes indicator

\footnotetext{
${ }^{24}$ We do not require that the social network links be reciprocal. In other words, Person A can be in Person B's social network (as reported by Person B), even if Person B is not in Person A's social network (as reported by Person A).

${ }^{25}$ Balance tests (not reported here but available from the authors) reveal that the number of treated network members is statistically unrelated with baseline characteristics.
} 
variables $W_{i v}^{k}$ for the respondent having one, two, three, four, or five or more voucher winners in his or her social network, as well as indicator variables $S_{i v}^{k}$ for the respondent having one, two, three, four, or five or more study participants in his or her social network (for each of these sets of indicator variables, the omitted category is zero).

The regression analysis conditions on the number of study participants in one's social network, because this variable is not exogenously determined, and is (mechanically) positively correlated with the number of voucher winners in one's social network. When controlling for number of study participants in one's social network, the regression coefficients on the number of voucher winners in one's social network can be interpreted as causal. Rather than imposing a particular functional form (e.g., a linear relationship), we specify voucher winners and study participants in the social network via a set of indicator variables to capture nonlinear effects. The coefficients of interest in the regression are the $\gamma_{k}$ coefficients on the number of voucher winners in one's social network.

Regression results are in Table 9. For space considerations, we show only the specifications where dependent variables are expressed in inverse hyperbolic sine transformation (IHST). ${ }^{26}$ In Panel A the dependent variable is the IHST of fertilizer use on maize, while in Panel B it is the IHST of fertilizer use on all crops. Coefficients for each of the three seasons (2011, 2012, and 2013) are presented in columns 1-3, and in column 4 we show results for the average of the post-voucher-season (2012 and 2013) outcomes. For each regression we report the $\gamma_{k}$ coefficients as well as the p-value of the F-test of the joint significance of the $\gamma_{k}$ coefficients in that regression.

In the season for which the voucher was offered, 2011, social network effects in both panels are typically negative in sign, but tests of joint significance do not reject the null of zero effect at conventional significance levels. ${ }^{27}$ In 2012, there are positive social network effects on fertilizer use on maize (jointly significant at the $10 \%$ level), and in 2013 there are positive social network effects on fertilizer use on all crops (jointly significant at the $1 \%$ level). On average over the 2012-2013 seasons, social network effects are positive and jointly statistically significant at the $5 \%$ level for fertilizer use on all crops, and marginally statistically significant (with p-value 0.11) for fertilizer use on maize. That these

\footnotetext{
${ }^{26}$ Regressions for dependent variables expressed in levels yield very similar conclusions, although they are often less precise.

${ }^{27}$ A possible explanation for these negative coefficients could be that individuals with social network members who received vouchers adopt a "wait and see" approach to fertilizer, holding off on their own investments until they can observe the returns experienced by others.
} 
impacts of social network voucher receipt occur only in years subsequent to the voucher distribution season is consistent with learning about fertilizer impacts in one's social network. It also seems sensible that statistically significant social network effects occur first (2012) for fertilizer use on maize (which the input package was designed for) and only later (2013) for fertilizer use on all crops.

The impacts on fertilizer use of voucher winning in one's social network are large in magnitude. For example, in the regression for fertilizer use on all crops on average over the 2012-13 seasons (Panel B, column 4), the impact of having one voucher winner in one's social network is nearly equal in magnitude to the impact of winning a voucher oneself (both coefficients are about 0.5). The coefficient estimates on having two or more voucher winners in one's social network are even larger, ranging in magnitude from 0.86 to 1.37 . The fact that voucher winning in one's social network has effects equal to or larger than effects of winning oneself is also consistent with learning being the primary channel of the voucher impacts, as opposed to the wealth channel.

Another broad pattern of note is that the effects of voucher winning in the social network appear to be nonlinear. There is typically a positive effect of having one voucher winner in the social network, and a somewhat larger effect of having two, but the effect appears to flatten thereafter, with not much additional impact of having three, four, or five or more winners in the social network (relative to having two).

\section{Conclusion}

We report the results of a randomized experiment testing impacts of a subsidy for modern agricultural inputs (fertilizer and improved seeds) on input utilization, agricultural output, and other household outcomes. We find substantial and persistent impacts (spanning three years following the one-time subsidy) on all these outcomes.

Our results are consistent with a set of theoretical models that predict persistence of one-time subsidies, and inconsistent with others that do not have such a persistence feature. In particular, our findings are consistent with models in which individuals must learn the returns to new technologies, via own experience or the experience of others in their social network. Winning the voucher lottery raises individual reports of expected returns to fertilizer. In ad-

dition, individual fertilizer use is strongly influenced by the number of voucher 
winners in one's social network. Both these patterns are consistent with the learning channel. Given the expense of permanent fertilizer subsidies in many sub-Saharan African countries that have adopted them, the results here motivate a more careful examination of whether the goals of permanent subsidies can be met with temporary subsidies that overcome barriers to experimentation and learning. 


\section{References}

Bandiera, O. and I. Rasul, "Social networks and technology adoption in Northern Mozambique," Econ. J., 2006, 116, 869-902.

Burbidge, John B., Lonnie Magee, and A. Leslie Robb, "Alternative Transformations to Handle Extreme Values of the Dependent Variable," Journal of the American Statistical Association, 1988, 83 (401), 123-27.

Caselli, Francesco and William Coleman, "Cross-country technology diffusion: the case of computers," Am. Econ. Rev., 2001, 91 (2), 328-35.

Chibwana, C., M. Fisher, C. Jumbe, W. Masters, and G. Shively, "Measuring the Impacts of Malawi's Farm Input Subsidy Program," 2010.

Comin, Diego and B. Hobijn, "Cross country technology adoption: making the theories face the facts," J. Monet. Econ., 2004, 51, 39-83.

Conley, T. and C. Udry, "Learning about a new technology: pineapple in Ghana," Am. Econ. Rev., 2010, 100 (1), 35-69.

Dercon, Stefan and Luc Christiaensen, "Consumption risk, technology adoption and poverty traps: evidence from Ethiopia," World Bank Policy Res. Work. Pap., 2007, (4257).

Dorward, A. and E Chirwa, "The Malawi agricultural input subsidy programme: 2005/06 to 2008/09," International Journal of Agricultural Sustainability, 2011, 9 (1), 232-247.

Druilhe, Zoe and Jesus Barreiro-Hurle, "Fertilizer Subsidies in SubSaharan Africa," ESA Working Paper 12-04, FAO July 2012.

Duflo, Esther, Michael Kremer, and Jonathan Robinson, "Nudging Farmers to Use Fertilizer: Theory and Experimental Evidence from Kenya," American Economic Review, 2011, 101 (6), 2350-2390.

Dupas, P., "Short-run subsidies and long-run adoption of new health products: evidence from a field experiment," Econometrica, 2014, 82 (1), 197-228.

Ellis, Frank, Agricultural Policies in Developing Countries, Cambridge, UK: Cambridge University Press., 1992. 
Evenson, Robert and Douglas Gollin, "Assessing the Impact of the Green Revolution, 1960 to 2000," Science, 2003, 300 (5620), 758-762.

Foster, Andrew D. and Mark R. Rosenzweig, "Learning by doing and learning from others: human capital and technical change in agriculture," $J$. Polit. Econ., 1995, 103 (6), 1176-209.

_ and _ , "Should poor farmers use more inputs?," 2009.

_ and _, "Microeconomics of Technology Adoption," Annu. Rev. Econ., 2010, 2, 395-424.

Gine, Xavier and Stephan Klonner, "Credit constraints as a barrier to technology adoption by the poor: lessons from South Indian small-scale fishery," World Bank Policy Res. Work. Pap., 2005, 3665.

IFAD, Rural Poverty Report 2009, International Fund for Agricultural Development (IFAD), 2011.

Jayne, T., D. Mather, N. Mason, and J. Ricker-Gilbert, "How Do Fertilizer Subsidy Programs Affect Total Fertilizer Use in Sub-Saharan Africa? Crowing out, Diversion, and Benefit/Cost Assessments," Agricultural Economics, 2013, 44 (6).

Jayne, T.S. and Shahidur Rashid, "Input Subsidy Programs in Sub-Saharan Africa: A Synthesis of Recent Evidence," Agricultural Economics, 2013, (44).

Kremer, Michael and Edward Miguel, "The illusion of sustainability.," $Q$. J. Econ., 2007, 122, 1007-65.

Lunduka, Rodney, Jacob Ricker-Gilbert, and Monica Fisher, "What are the farm-level impacts of Malawi's farm input subsidy program? A critical review," Agricultural Economics, 2013, 44, 563-579.

Marenya, P. and C. B. Barrett, "State-conditional Fertilizer yield response on western Kenyan farms," Amer. J. Agr. Econ., 2009, 91 (4), 991-1006.

McKenzie, David, "Beyond Baseline and Follow-up: The Case for More T in Experiments," J. Dev. Econ., 2012, 99 (2), 201-221.

Minot, N., "Smart fertilizer subsidies in sub-Saharan Africa: new wine or just new bottles?," Technical Report, IFPRI 2009. 
- and T. Benson, "Fertilizer Subsidies in Africa: Are Vouchers the Answer?," Technical Report Brief 60, IFPRI, Washington, D.C. 2009.

Miyata, S. and Y. Sawada, 'Learning, risk, and credit in households' new technology investments: the case of aquaculture in rural Indonesia," 2007.

Morris, Michael, Valerie A. Kelly, Ron J. Kopicki, and Derek Byerlee, Fertilizer Use in African Agriculture: Lessons Learned and Good Practice Guidelines, Washington, DC: World Bank, 2007.

Moser, C. and C. Barrett, "The complex dynamics of smallholder technology adoption: the case of SRI in Madagascar," Agricultural Economics, 2006.

Munshi, Kaivan, "Social learning in a heterogeneous population: technology diffusion in the Indian green revolution," J. Dev. Econ., 2006, 73 (1), 185-215.

Nankani, G., M. Baxter, R. Scobey, and J. Perumalpillai-Essex, "Mozambique Agricultural Development Strategy Stimulating Smallholder Agricultural Growth," Technical Report, World Bank 2006.

Oster, Emily and Rebecca Thornton, "Determinants of Technology Adoption: Peer Effects in Menstrual Cup Take-Up," Journal of the European Economic Association, December 2012, 10 (6), 1263-1293.

Pan, Lei and Luc Christiaensen, "Who is vouching for the input voucher? Decentralized targeting and elite capture in Tanzania," World Bank Policy Res. Work. Pap., 2011, 5651.

Sachs, Jeffrey D., "The Case for Fertilizer Subsidies for Subsistence Farmers," Unpublished, 2004.

Schultz, Theodore W., Transforming Traditional Agriculture, New Haven, CT: Yale University Press, 1964.

Sharma, V.P. and H. Thaker, "Fertilizer Subsidy in India: Who are the Beneficiaries?," Technical Report, Indian Institute of Management 2009.

Tarozzi, A., A. Mahajan, B. Blackburn, D. Kopf, L. Krishnan, and J. Yoong, "Micro-loans, Insecticide-Treated Bednets and Malaria: Evidence from a Randomized Controlled Trial in Orissa (India)," Am. Econ. Rev., July 2014, 104 (7), 1909-41.

WorldBank, World Development Report 2008: Agriculture for Development, Washington, DC: World Bank, 2007. 
Table 1: Summary Statistics and Test of Balance across Treatment Conditions

\begin{tabular}{|c|c|c|c|c|c|c|c|c|}
\hline & \multicolumn{4}{|c|}{ 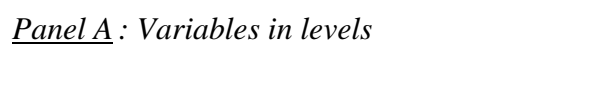 } & \multicolumn{4}{|c|}{$\begin{array}{l}\text { Panel B }: \text { Select variables in inverse } \\
\text { hyperbolic sine transformation (IHST) }\end{array}$} \\
\hline & $\underline{\text { Full }}$ & $\frac{\text { Control }}{\text { group }}$ & $\frac{\text { Treatment }}{\text { group }}$ & p-value & $\underline{\text { Full }}$ & $\frac{\text { Control }}{\text { group }}$ & $\frac{\text { Treatment }}{\text { group }}$ & p-value \\
\hline HH head years of education & $\begin{array}{c}4.73 \\
{[3.17]}\end{array}$ & $\begin{array}{c}4.77 \\
{[3.32]}\end{array}$ & $\begin{array}{c}4.7 \\
{[3.01]}\end{array}$ & 0.8188 & & & & \\
\hline HH head male (indicator) & $\begin{array}{c}0.85 \\
{[0.36]}\end{array}$ & $\begin{array}{c}0.85 \\
{[0.36]}\end{array}$ & $\begin{array}{c}0.85 \\
{[0.36]}\end{array}$ & 0.9311 & & & & \\
\hline HH head years of age & $\begin{array}{c}46.12 \\
{[13.92]}\end{array}$ & $\begin{array}{c}45.82 \\
{[14.09]}\end{array}$ & $\begin{array}{c}46.43 \\
{[13.76]}\end{array}$ & 0.6275 & & & & \\
\hline HH head literate (indicator) & $\begin{array}{c}0.78 \\
{[0.42]}\end{array}$ & $\begin{array}{c}0.79 \\
{[0.41]}\end{array}$ & $\begin{array}{c}0.76 \\
{[0.43]}\end{array}$ & 0.4262 & & & & \\
\hline Area farmed (hectares)* & $\begin{array}{c}3.28 \\
{[3.03]}\end{array}$ & $\begin{array}{c}3.37 \\
{[2.98]}\end{array}$ & $\begin{array}{c}3.18 \\
{[3.07]}\end{array}$ & 0.4900 & $\begin{array}{c}1.47 \\
{[0.62]}\end{array}$ & $\begin{array}{c}1.49 \\
{[0.62]}\end{array}$ & $\begin{array}{c}1.44 \\
{[0.63]}\end{array}$ & 0.3942 \\
\hline Fertilizer used (kg)* & $\begin{array}{c}25.04 \\
{[59.44]}\end{array}$ & $\begin{array}{c}27.05 \\
{[63.54]}\end{array}$ & $\begin{array}{c}22.9 \\
{[54.76]}\end{array}$ & 0.4290 & $\begin{array}{c}1 \\
{[1.95]}\end{array}$ & $\begin{array}{c}1.05 \\
{[1.99]}\end{array}$ & $\begin{array}{c}0.95 \\
{[1.90]}\end{array}$ & 0.5645 \\
\hline Fertilizer used (kg/ha)* & $\begin{array}{c}14.07 \\
{[42.33]}\end{array}$ & $\begin{array}{c}15.17 \\
{[44.37]}\end{array}$ & $\begin{array}{c}12.88 \\
{[40.08]}\end{array}$ & 0.5421 & $\begin{array}{c}0.83 \\
{[1.65]}\end{array}$ & $\begin{array}{c}0.88 \\
{[1.69]}\end{array}$ & $\begin{array}{c}0.78 \\
{[1.59]}\end{array}$ & 0.4813 \\
\hline Fertilizer used (indicator) & $\begin{array}{c}0.22 \\
{[0.41]}\end{array}$ & $\begin{array}{c}0.22 \\
{[0.42]}\end{array}$ & $\begin{array}{c}0.21 \\
{[0.41]}\end{array}$ & 0.7230 & & & & \\
\hline Improved seeds used (kg)* & $\begin{array}{c}21.66 \\
{[35.45]}\end{array}$ & $\begin{array}{c}21.31 \\
{[35.27]}\end{array}$ & $\begin{array}{c}22.03 \\
{[35.70]}\end{array}$ & 0.8197 & $\begin{array}{c}1.88 \\
{[1.87]}\end{array}$ & $\begin{array}{c}1.81 \\
{[1.88]}\end{array}$ & $\begin{array}{c}1.96 \\
{[1.87]}\end{array}$ & 0.3754 \\
\hline Improved seeds used (kg/ha)* & $\begin{array}{c}9.44 \\
{[14.59]}\end{array}$ & $\begin{array}{c}9.23 \\
{[14.82]}\end{array}$ & $\begin{array}{c}9.66 \\
{[14.36]}\end{array}$ & 0.7395 & $\begin{array}{c}1.51 \\
{[1.51]}\end{array}$ & $\begin{array}{c}1.46 \\
{[1.52]}\end{array}$ & $\begin{array}{c}1.56 \\
{[1.51]}\end{array}$ & 0.4501 \\
\hline Maize production $(\mathrm{kg})^{*}$ & $\begin{array}{c}2164.75 \\
{[2512.79]}\end{array}$ & $\begin{array}{c}2208.08 \\
{[2377.05]}\end{array}$ & $\begin{array}{c}2117.97 \\
{[2655.78]}\end{array}$ & 0.6912 & $\begin{array}{c}7.25 \\
{[0.97]}\end{array}$ & $\begin{array}{c}7.29 \\
{[0.94]}\end{array}$ & $\begin{array}{c}7.21 \\
{[0.99]}\end{array}$ & 0.3748 \\
\hline Maize yield (kg/ha)* & $\begin{array}{c}947.48 \\
{[1066.55]}\end{array}$ & $\begin{array}{c}979.45 \\
{[1114.46]}\end{array}$ & $\begin{array}{c}913.08 \\
{[1013.70]}\end{array}$ & 0.4886 & $\begin{array}{c}6.45 \\
{[0.95]}\end{array}$ & $\begin{array}{c}6.46 \\
{[1.00]}\end{array}$ & $\begin{array}{c}6.44 \\
{[0.91]}\end{array}$ & 0.8714 \\
\hline Maize sold (kg)* & $\begin{array}{c}510.6 \\
{[1248.19]}\end{array}$ & $\begin{array}{c}454.0 \\
{[1056.79]}\end{array}$ & $\begin{array}{c}571.2 \\
{[1424.98]}\end{array}$ & 0.3047 & $\begin{array}{c}3.0 \\
{[3.26]}\end{array}$ & $\begin{array}{c}3.0 \\
{[3.24]}\end{array}$ & $\begin{array}{c}2.9 \\
{[3.29]}\end{array}$ & 0.8404 \\
\hline Sold any maize (indicator) & $\begin{array}{c}0.49 \\
{[0.50]}\end{array}$ & $\begin{array}{c}0.50 \\
{[0.50]}\end{array}$ & $\begin{array}{c}0.48 \\
{[0.50]}\end{array}$ & 0.7439 & & & & \\
\hline Irrigated (indicator) & $\begin{array}{c}0.05 \\
{[0.22]}\end{array}$ & $\begin{array}{c}0.05 \\
{[0.21]}\end{array}$ & $\begin{array}{c}0.05 \\
{[0.22]}\end{array}$ & 0.7083 & & & & \\
\hline $\begin{array}{l}\text { Years used fertilizer } \\
\text { (out of last } 9 \text { years) }\end{array}$ & $\begin{array}{c}1.03 \\
{[2.16]}\end{array}$ & $\begin{array}{c}1.05 \\
{[2.19]}\end{array}$ & $\begin{array}{c}1.00 \\
{[2.13]}\end{array}$ & 0.7811 & & & & \\
\hline
\end{tabular}

Note: Means of variables are presented, with standard deviations in brackets. Agricultural data refer to 2009-2010 season, prior to treatment assignment. Number of observations is 514 in full sample, 267 in control group, and 247 in treatment group. To reduce influence of outliers, starred $(*)$ variables in levels (Panel A) have top $1 \%$ of values replaced by 99th percentile. Inverse hyperbolic sine transformation (IHST) is similar to log transformation in helping reduce influence of outliers, but is defined at zero (Burbidge et al. 1988). 
Table 2: Impact of Treatment on Voucher Receipt and Voucher Use

$$
\text { Dependent variable: } \begin{gathered}
\text { Voucher received } \\
\text { (indicator) }
\end{gathered} \quad \begin{gathered}
\text { Voucher used } \\
\text { (indicator) }
\end{gathered}
$$

$\begin{array}{lcc}\text { Treatment } & 0.36^{* * *} & 0.29^{* * * *} \\ & {[0.043]} & {[0.046]} \\ \text { Observations } & 514 & 514 \\ \text { Mean in control group } & 0.13 & 0.12\end{array}$

*** $\mathrm{p}<0.01, * * \mathrm{p}<0.05, * \mathrm{p}<0.1$

Note: Robust standard errors in brackets. Dependent variables are indicators equal to 1 if respondent received their input subsidy voucher (column 1) or used an input subsidy voucher (column 2) at the start of the 2010-11 agricultural season. Treatment is randomized within each of 41 villages. Each regression includes village fixed effects. 
Table 3: Impact of Treatment on Use of Fertilizer and Improved Seeds

\begin{tabular}{|c|c|c|c|c|c|c|}
\hline Dependent variab & $\begin{array}{c}\text { Fertilizer on } \\
\text { maize (kg) }\end{array}$ & $\begin{array}{c}\text { Fertilizer on } \\
\text { maize (kg/ha) }\end{array}$ & $\begin{array}{c}\text { Fertilizer on } \\
\text { other crops } \\
(\mathrm{kg})\end{array}$ & $\begin{array}{l}\text { Fertilizer on all } \\
\text { crops (kg) }\end{array}$ & $\begin{array}{l}\text { Value of } \\
\text { fertilizer on all } \\
\text { crops (MZN) }\end{array}$ & $\begin{array}{c}\text { Improved } \\
\text { seeds (kg/ha) }\end{array}$ \\
\hline
\end{tabular}

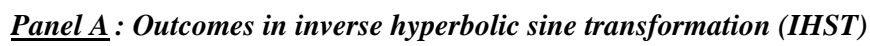

\begin{tabular}{|c|c|c|c|c|c|c|c|c|}
\hline \multirow[t]{3}{*}{$\begin{array}{c}2011 \\
\text { season }\end{array}$} & Treatment & $\begin{array}{c}0.76^{* * *} \\
{[0.19]}\end{array}$ & $\begin{array}{c}0.67 * * * \\
{[0.20]}\end{array}$ & $\begin{array}{l}0.040 \\
{[0.15]}\end{array}$ & $\begin{array}{c}0.61 * * * \\
{[0.22]}\end{array}$ & $\begin{array}{l}0.98 * * \\
{[0.36]}\end{array}$ & $\begin{array}{c}0.49 * * * \\
{[0.17]}\end{array}$ & $\begin{array}{c}0.44 * * * \\
{[0.14]}\end{array}$ \\
\hline & $\mathrm{N}$ & & & & & & & \\
\hline & Mean, cont. grp. & 510 & 505 & 504 & 503 & 503 & 496 & 491 \\
\hline \multirow{4}{*}{$\begin{array}{c}2012 \\
\text { season }\end{array}$} & Treatment & $0.32 * *$ & $0.31^{* *}$ & $0.38 * *$ & $0.46^{* * *}$ & $0.70^{* * *}$ & 0.0083 & 0.10 \\
\hline & & {$[0.13]$} & [0.12] & [0.15] & [0.15] & [0.24] & [0.14] & {$[0.14]$} \\
\hline & $\mathrm{N}$ & 457 & 449 & 456 & 452 & 452 & 454 & 447 \\
\hline & Mean, cont. grp. & 0.71 & 0.59 & 0.90 & 1.37 & 2.48 & 1.85 & 1.45 \\
\hline \multirow{4}{*}{$\begin{array}{c}2013 \\
\text { season }\end{array}$} & Treatment & $0.31 * *$ & $0.26^{* *}$ & 0.18 & 0.28 & 0.42 & 0.19 & 0.16 \\
\hline & & [0.13] & [0.11] & {$[0.15]$} & {$[0.17]$} & [0.29] & {$[0.16]$} & [0.13] \\
\hline & $\mathrm{N}$ & 473 & 471 & 472 & 470 & 470 & 466 & 464 \\
\hline & Mean, cont. grp. & 0.70 & 0.61 & 1.13 & 1.44 & 2.55 & 1.75 & 1.38 \\
\hline \multirow{4}{*}{$\begin{array}{c}\text { Average, } \\
\text { 2012-2013 } \\
\text { seasons }\end{array}$} & Treatment & $0.36 * * *$ & $0.34^{* * *}$ & $0.32^{* *}$ & $0.47^{* * *}$ & $0.72 * * *$ & 0.098 & 0.14 \\
\hline & & [0.12] & [0.10] & [0.12] & {$[0.14]$} & [0.24] & {$[0.12]$} & {$[0.10]$} \\
\hline & $\mathrm{N}$ & 495 & 493 & 496 & 495 & 495 & 494 & 492 \\
\hline & Mean, cont. grp. & 0.70 & 0.60 & 0.98 & 1.37 & 2.44 & 1.81 & 1.40 \\
\hline \multicolumn{9}{|c|}{ Panel B: Outcomes in levels } \\
\hline \multirow{4}{*}{$\begin{array}{c}2011 \\
\text { season }\end{array}$} & Treatment & $17.16^{* * *}$ & $12.28 *$ & 3.294 & $22.72 * *$ & $636.0 * *$ & 3.57 & 3.15 \\
\hline & & [5.12] & {$[6.94]$} & [6.492] & [8.897] & [251.0] & {$[3.40]$} & [2.12] \\
\hline & $\mathrm{N}$ & 510 & 505 & 504 & 503 & 503 & 496 & 491 \\
\hline & Mean, cont. grp. & 22.32 & 15.41 & 29.08 & 51.85 & 1456 & 19.85 & 8.701 \\
\hline \multirow{4}{*}{$\begin{array}{c}2012 \\
\text { season }\end{array}$} & Treatment & $6.37 *$ & 13.36 & $14.46^{* *}$ & $17.98^{* *}$ & $505.3^{* *}$ & $-3.92 *$ & 1.25 \\
\hline & & {$[3.40]$} & [9.03] & [6.858] & [7.539] & {$[211.6]$} & {$[2.10]$} & [2.68] \\
\hline & $\mathrm{N}$ & 457 & 449 & 456 & 452 & 452 & 454 & 447 \\
\hline & Mean, cont. grp. & 18.83 & 10.68 & 18.61 & 39.86 & 1116 & 18.82 & 9.109 \\
\hline \multirow{4}{*}{$\begin{array}{c}2013 \\
\text { season }\end{array}$} & Treatment & 7.50 & $5.76^{*}$ & 3.179 & $12.84^{*}$ & $358.3^{*}$ & 3.13 & 0.92 \\
\hline & & [5.48] & [3.23] & [6.203] & [6.698] & [187.7] & [2.52] & [1.20] \\
\hline & $\mathrm{N}$ & 473 & 471 & 472 & 470 & 470 & 466 & 464 \\
\hline & Mean, cont. grp. & 17.90 & 11.19 & 26.76 & 45.01 & 1259 & 18.47 & 8.765 \\
\hline \multirow{4}{*}{$\begin{array}{c}\text { Average, } \\
\text { 2012-2013 } \\
\text { seasons }\end{array}$} & Treatment & $8.65^{*}$ & $11.82^{*}$ & 9.060 & $19.13^{* * *}$ & $534.5^{* * *}$ & -0.77 & 1.41 \\
\hline & & [4.34] & [6.21] & [5.531] & [6.385] & [179.6] & {$[1.52]$} & [1.58] \\
\hline & $\mathrm{N}$ & 495 & 493 & 496 & 495 & 495 & 494 & 492 \\
\hline & Mean, cont. grp. & 18.48 & 10.65 & 21.78 & 41.31 & 1156 & 19.03 & 8.727 \\
\hline
\end{tabular}

$* * * \mathrm{p}<0.01, * * \mathrm{p}<0.05, * \mathrm{p}<0.1$

Note: Robust standard errors in brackets. Vouchers distributed at start of 2011 agricultural season. No vouchers were distributed for the 2012 and 2013 seasons. Dependent variables for "Average, 2012-2013 seasons" rows are the average of the dependent variables for the 2012 and 2013 seasons (if either one is missing, the value for the non-missing year is used.) Treatment is randomized within each of 41 villages. Each regression includes village fixed effects. MZN = Mozambican meticals (approx. 27 MZN/USD). 
Table 4: Impact of Treatment on Farm Production and Market Sales

\begin{tabular}{|c|c|c|c|c|c|c|}
\hline Dependent variable: & $\begin{array}{c}\text { Maize } \\
\text { production (kg) }\end{array}$ & $\begin{array}{l}\text { Maize yield } \\
\text { (kg/ha) }\end{array}$ & $\begin{array}{l}\text { Other crop } \\
\text { production } \\
(\mathrm{MZN})\end{array}$ & $\begin{array}{l}\text { Production, all } \\
\text { crops (MZN) }\end{array}$ & $\begin{array}{l}\text { Maize sales } \\
\text { (MZN) }\end{array}$ & $\begin{array}{l}\text { All crop sales } \\
\text { (MZN) }\end{array}$ \\
\hline
\end{tabular}

Panel A : Outcomes in inverse hyperbolic sine transformation (IHST)

\begin{tabular}{|c|c|c|c|c|c|c|c|}
\hline \multirow[t]{3}{*}{$\begin{array}{c}2011 \\
\text { season }\end{array}$} & Treatment & $\begin{array}{c}0.050 \\
{[0.074]}\end{array}$ & $\begin{array}{c}0.23 * * \\
{[0.086]}\end{array}$ & $\begin{array}{l}-0.26 \\
{[0.28]}\end{array}$ & $\begin{array}{c}0.0037 \\
{[0.093]}\end{array}$ & $\begin{array}{l}-0.40 \\
{[0.29]}\end{array}$ & $\begin{array}{l}-0.47 \\
{[0.38]}\end{array}$ \\
\hline & $\mathrm{N}$ & 460 & 457 & 470 & 460 & 387 & 387 \\
\hline & Mean, cont. grp. & 7.14 & 6.29 & 5.51 & 9.11 & 2.46 & 4.49 \\
\hline \multirow{4}{*}{$\begin{array}{c}2012 \\
\text { season }\end{array}$} & Treatment & 0.087 & $0.25 * *$ & $0.81^{* * *}$ & 0.14 & 0.45 & 0.39 \\
\hline & & {$[0.096]$} & {$[0.12]$} & {$[0.30]$} & [0.097] & {$[0.36]$} & {$[0.42]$} \\
\hline & $\mathrm{N}$ & 442 & 436 & 462 & 442 & 449 & 449 \\
\hline & Mean, cont. grp. & 7.17 & 6.37 & 6.09 & 9.19 & 2.88 & 5.37 \\
\hline \multirow{4}{*}{$\begin{array}{l}2013 \\
\text { season }\end{array}$} & Treatment & 0.13 & $0.14 *$ & $0.45^{* *}$ & $0.19 * *$ & $0.64 * *$ & $0.77 * *$ \\
\hline & & {$[0.081]$} & [0.079] & {$[0.22]$} & {$[0.074]$} & {$[0.30]$} & [0.33] \\
\hline & $\mathrm{N}$ & 468 & 466 & 475 & 468 & 464 & 464 \\
\hline & Mean, cont. grp. & 7.19 & 6.38 & 6.71 & 9.22 & 3.56 & 6.05 \\
\hline \multirow{4}{*}{$\begin{array}{c}\text { Average, } \\
\text { 2012-2013 } \\
\text { seasons }\end{array}$} & Treatment & 0.11 & $0.19 * *$ & $0.62 * * *$ & $0.16^{* *}$ & $0.67 * *$ & $0.70 * *$ \\
\hline & & {$[0.071]$} & {$[0.077]$} & {$[0.19]$} & [0.069] & {$[0.30]$} & {$[0.32]$} \\
\hline & $\mathrm{N}$ & 492 & 491 & 496 & 492 & 493 & 493 \\
\hline & Mean, cont. grp. & 7.17 & 6.37 & 6.40 & 9.21 & 3.19 & 5.69 \\
\hline
\end{tabular}

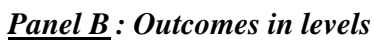

\begin{tabular}{|c|c|c|c|c|c|c|c|}
\hline \multirow[t]{3}{*}{ season } & Treatment & $\begin{array}{c}204.7 \\
{[158.1]}\end{array}$ & $\begin{array}{c}192.2^{* *} \\
{[87.3]}\end{array}$ & $\begin{array}{c}452.5 \\
{[836.4]}\end{array}$ & $\begin{array}{c}1,822 \\
{[1,505]}\end{array}$ & $\begin{array}{l}-29.8 \\
{[368]}\end{array}$ & $\begin{array}{c}369 \\
{[1,999]}\end{array}$ \\
\hline & $\mathrm{N}$ & 460 & 457 & 470 & 460 & 387 & 387 \\
\hline & Mean, cont. grp. & 1907 & 806.5 & 4556 & 14324 & 1450 & 8947 \\
\hline \multirow{4}{*}{$\begin{array}{c}2012 \\
\text { season }\end{array}$} & Treatment & 208.8 & $288.1^{*}$ & 2,974 & 3,740 & -173 & 1,781 \\
\hline & & [225.4] & [149.2] & {$[2,032]$} & {$[2,639]$} & [691] & {$[4,030]$} \\
\hline & $\mathrm{N}$ & 442 & 436 & 462 & 442 & 449 & 449 \\
\hline & Mean, cont. grp. & 2169 & 923.7 & 7468 & 19980 & 2844 & 17267 \\
\hline \multirow{4}{*}{$\begin{array}{c}2013 \\
\text { season }\end{array}$} & Treatment & $440.7 * *$ & 167.2 & 1,714 & $4,288 * *$ & 209 & 3,443 \\
\hline & & [211.4] & [105.0] & {$[1,063]$} & {$[1,586]$} & {$[473]$} & {$[2,915]$} \\
\hline & $\mathrm{N}$ & 468 & 466 & 475 & 468 & 464 & 464 \\
\hline & Mean, cont. grp. & 1932 & 927.9 & 6760 & 16699 & 2731 & 16313 \\
\hline \multirow{4}{*}{$\begin{array}{l}\text { Average, } \\
\text { 2012-2013 } \\
\text { seasons }\end{array}$} & Treatment & $335.7 * *$ & $248.7 * *$ & $2,149 *$ & $3,906 * *$ & 144 & 3,242 \\
\hline & & [161.1] & [107.6] & {$[1,086]$} & {$[1,528]$} & [433] & {$[2,871]$} \\
\hline & $\mathrm{N}$ & 492 & 491 & 496 & 492 & 493 & 493 \\
\hline & Mean, cont. grp. & 2018 & 907.3 & 7074 & 18094 & 2691 & 16215 \\
\hline
\end{tabular}

*** $\mathrm{p}<0.01, * * \mathrm{p}<0.05, * \mathrm{p}<0.1$

Note: Robust standard errors in brackets. See Table 3 for other notes. 
Table 5: Impact of Treatment on Consumption, Savings, and Assets

\begin{tabular}{|c|c|c|c|c|c|c|}
\hline Dependent variable: & $\begin{array}{l}\text { Per capita } \\
\text { daily } \\
\text { consumption } \\
\text { (MZN) }\end{array}$ & $\begin{array}{c}\text { Total savings } \\
(\mathrm{MZN})\end{array}$ & $\begin{array}{l}\text { Durable goods } \\
(\mathrm{MZN})\end{array}$ & $\begin{array}{l}\text { Livestock } \\
(\mathrm{MZN})\end{array}$ & $\begin{array}{c}\text { Food stocks } \\
(\mathrm{MZN})\end{array}$ & $\begin{array}{c}\text { Total assets } \\
\text { and savings } \\
(\mathrm{MZN})\end{array}$ \\
\hline
\end{tabular}

Panel A : Outcomes in inverse hyperbolic sine transformation (IHST)

\begin{tabular}{|c|c|c|c|c|c|c|c|}
\hline \multirow[t]{3}{*}{ season } & Treatment & $\begin{array}{c}0.0072 \\
{[0.042]}\end{array}$ & $\begin{array}{c}0.20 \\
{[0.25]}\end{array}$ & $\begin{array}{c}0.33 \\
{[0.25]}\end{array}$ & $\begin{array}{c}-0.020 \\
{[0.23]}\end{array}$ & $\begin{array}{c}0.10 \\
{[0.20]}\end{array}$ & $\begin{array}{c}0.12 \\
{[0.13]}\end{array}$ \\
\hline & $\mathrm{N}$ & 469 & 470 & 470 & 470 & 470 & 470 \\
\hline & Mean, cont. grp. & 4.34 & 6.25 & 8.00 & 8.99 & 7.61 & 10.3 \\
\hline \multirow{4}{*}{$\begin{array}{c}2012 \\
\text { season }\end{array}$} & Treatment & $0.14 * * *$ & $0.66^{* *}$ & 0.10 & 0.44 & 0.34 & 0.17 \\
\hline & & {$[0.036]$} & {$[0.27]$} & [0.19] & {$[0.27]$} & {$[0.25]$} & {$[0.12]$} \\
\hline & $\mathrm{N}$ & 462 & 462 & 462 & 462 & 462 & 462 \\
\hline & Mean, cont. grp. & 4.24 & 5.14 & 8.34 & 8.73 & 7.46 & 10.3 \\
\hline \multirow{4}{*}{$\begin{array}{c}2013 \\
\text { season }\end{array}$} & Treatment & 0.050 & 0.43 & 0.10 & $0.70 *$ & 0.22 & $0.26^{* *}$ \\
\hline & & {$[0.053]$} & {$[0.27]$} & {$[0.23]$} & {$[0.35]$} & {$[0.14]$} & {$[0.12]$} \\
\hline & $\mathrm{N}$ & 475 & 475 & 475 & 475 & 475 & 475 \\
\hline & Mean, cont. grp. & 4.26 & 6.42 & 8.28 & 8.48 & 8.18 & \\
\hline \multirow{4}{*}{$\begin{array}{c}\text { Average, } \\
\text { 2012-2013 } \\
\text { seasons }\end{array}$} & Treatment & $0.095 * *$ & $0.51 * *$ & 0.12 & $0.60 * *$ & $0.30 *$ & $0.22 *$ \\
\hline & & {$[0.036]$} & {$[0.20]$} & [0.19] & {$[0.29]$} & {$[0.15]$} & {$[0.11]$} \\
\hline & $\mathrm{N}$ & 496 & 496 & 496 & 496 & 496 & 496 \\
\hline & Mean, cont. grp. & 4.26 & 5.78 & 8.30 & 8.59 & 7.81 & 10.4 \\
\hline
\end{tabular}

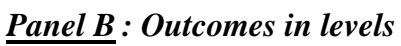

\begin{tabular}{|c|c|c|c|c|c|c|c|}
\hline \multirow[t]{3}{*}{$\begin{array}{l}2011 \\
\text { season }\end{array}$} & Treatment & $\begin{array}{c}0.78 \\
{[3.65]}\end{array}$ & $\begin{array}{c}868.7 \\
{[1,047.5]}\end{array}$ & $\begin{array}{c}3,134.9 \\
{[2,286.8]}\end{array}$ & $\begin{array}{c}4,456.9 \\
{[4,465.0]}\end{array}$ & $\begin{array}{c}-41.4 \\
{[742.9]}\end{array}$ & $\begin{array}{c}9,318.2 \\
{[7,097.0]}\end{array}$ \\
\hline & $\mathrm{N}$ & 469 & 470 & 470 & 470 & 470 & 470 \\
\hline & Mean, cont. grp. & 78.81 & 4645 & 11261 & 30815 & 7040 & 54376 \\
\hline \multirow[t]{3}{*}{$\begin{array}{c}2012 \\
\text { season }\end{array}$} & Treatment & $\begin{array}{c}14.03 * * * \\
{[4.58]}\end{array}$ & $\begin{array}{c}1,855.8 * * * \\
{[619.4]}\end{array}$ & $\begin{array}{c}3,743.3 \\
{[2,573.7]}\end{array}$ & $\begin{array}{c}1,056.9 \\
{[3,996.8]}\end{array}$ & $\begin{array}{c}1,916.4 \\
{[1,163.9]}\end{array}$ & $\begin{array}{c}7,016.3 \\
{[6,295.0]}\end{array}$ \\
\hline & $\mathrm{N}$ & 462 & 462 & 462 & 462 & 462 & 462 \\
\hline & Mean, cont. grp. & 71.65 & 3572 & 11721 & 34192 & 6339 & 58385 \\
\hline \multirow[t]{3}{*}{$\begin{array}{l}2013 \\
\text { season }\end{array}$} & Treatment & $\begin{array}{c}6.81 \\
{[4.85]}\end{array}$ & $\begin{array}{c}2,759.5 * * * \\
{[995.0]}\end{array}$ & $\begin{array}{c}5,165.6 \\
{[3,435.4]}\end{array}$ & $\begin{array}{c}5,493.7 \\
{[4,765.9]}\end{array}$ & $\begin{array}{c}1,888.0 * \\
{[944.0]}\end{array}$ & $\begin{array}{c}14,956.0 \\
{[10,181.9]}\end{array}$ \\
\hline & $\mathrm{N}$ & 475 & 475 & 475 & 475 & 475 & 475 \\
\hline & Mean, cont. grp. & 71.70 & 4618 & 12426 & 33142 & 7666 & 61986 \\
\hline $\begin{array}{l}\text { Average, } \\
\text { 2012-2013 }\end{array}$ & Treatment & $\begin{array}{c}10.59 * * \\
{[4.11]}\end{array}$ & $\begin{array}{c}2,122.7 * * * \\
{[583.1]}\end{array}$ & $\begin{array}{c}4,696.3 \\
{[2,882.8]}\end{array}$ & $\begin{array}{c}4,303.3 \\
{[3,962.3]}\end{array}$ & $\begin{array}{c}2,042.5 * * * \\
{[694.7]}\end{array}$ & $\begin{array}{c}11,502.9 \\
{[7,818.4]}\end{array}$ \\
\hline seasons & $\begin{array}{l}\mathrm{N} \\
\text { Mean, cont. grp. }\end{array}$ & $\begin{array}{c}496 \\
72.28\end{array}$ & $\begin{array}{c}496 \\
4312\end{array}$ & $\begin{array}{c}496 \\
12344\end{array}$ & $\begin{array}{c}496 \\
33374\end{array}$ & $\begin{array}{c}496 \\
6952\end{array}$ & $\begin{array}{c}496 \\
61161\end{array}$ \\
\hline
\end{tabular}

$* * * \mathrm{p}<0.01, * * \mathrm{p}<0.05, * \mathrm{p}<0.1$

Note: Robust standard errors in brackets. See Table 3 for other notes. 
Table 6: Impact of Treatment on Housing Improvements

Dependent variable: Indicator for making improvement in the last 12 months in...

\begin{tabular}{|c|c|c|c|c|c|c|c|c|}
\hline & & $\begin{array}{l}\text { Any aspect of } \\
\text { housing }\end{array}$ & Walls & Ceiling & Floor & Latrine & $\begin{array}{l}\text { Energy for } \\
\text { cooking }\end{array}$ & $\begin{array}{c}\text { Energy for } \\
\text { light }\end{array}$ \\
\hline \multirow[t]{3}{*}{$\begin{array}{l}2011 \\
\text { season }\end{array}$} & Treatment & $\begin{array}{c}-0.04 \\
{[0.03]}\end{array}$ & $\begin{array}{c}0.00 \\
{[0.02]}\end{array}$ & $\begin{array}{c}0.01 \\
{[0.02]}\end{array}$ & $\begin{array}{c}-0.04^{* *} \\
{[0.02]}\end{array}$ & $\begin{array}{c}-0.01 \\
{[0.02]}\end{array}$ & $\begin{array}{c}-0.01 \\
{[0.01]}\end{array}$ & $\begin{array}{c}-0.01 \\
{[0.01]}\end{array}$ \\
\hline & $\mathrm{N}$ & 470 & 470 & 470 & 470 & 470 & 470 & 470 \\
\hline & Mean, cont. grp. & 0.128 & 0.0248 & 0.0248 & 0.0496 & 0.0372 & 0.0165 & 0.0165 \\
\hline \multirow[t]{3}{*}{$\begin{array}{l}2012 \\
\text { season }\end{array}$} & Treatment & $\begin{array}{c}0.04 \\
{[0.04]}\end{array}$ & $\begin{array}{c}0.02 \\
{[0.03]}\end{array}$ & $\begin{array}{l}-0.01 \\
{[0.02]}\end{array}$ & $\begin{array}{c}0.03 \\
{[0.03]}\end{array}$ & $\begin{array}{l}-0.02 \\
{[0.02]}\end{array}$ & $\begin{array}{l}-0.00 \\
{[0.01]}\end{array}$ & $\begin{array}{c}0.02 \\
{[0.03]}\end{array}$ \\
\hline & $\mathrm{N}$ & 462 & 462 & 462 & 462 & 462 & 462 & 462 \\
\hline & Mean, cont. grp. & 0.215 & 0.0729 & 0.0810 & 0.0607 & 0.0648 & 0.00810 & 0.0729 \\
\hline \multirow[t]{3}{*}{$\begin{array}{l}2013 \\
\text { season }\end{array}$} & Treatment & $\begin{array}{c}0.04 \\
{[0.04]}\end{array}$ & $\begin{array}{c}0.08^{* * *} \\
{[0.03]}\end{array}$ & $\begin{array}{c}0.05^{*} \\
{[0.03]}\end{array}$ & $\begin{array}{c}0.05^{*} \\
{[0.03]}\end{array}$ & $\begin{array}{c}0.04 \\
{[0.02]}\end{array}$ & $\begin{array}{c}0.02 \\
{[0.02]}\end{array}$ & $\begin{array}{c}0.03 \\
{[0.02]}\end{array}$ \\
\hline & $\mathrm{N}$ & 475 & 475 & 475 & 475 & 475 & 475 & 475 \\
\hline & Mean, cont. grp. & 0.214 & 0.0363 & 0.105 & 0.0927 & 0.0685 & 0.0565 & 0.0887 \\
\hline \multirow{3}{*}{$\begin{array}{c}\text { Average, } \\
2012-2013 \\
\text { seasons }\end{array}$} & Treatment & $\begin{array}{l}0.04 * * \\
{[0.02]}\end{array}$ & $\begin{array}{c}0.06^{* * *} \\
{[0.02]}\end{array}$ & $\begin{array}{c}0.03 \\
{[0.02]}\end{array}$ & $\begin{array}{l}0.04 * \\
{[0.02]}\end{array}$ & $\begin{array}{c}0.02 \\
{[0.02]}\end{array}$ & $\begin{array}{c}0.01 \\
{[0.01]}\end{array}$ & $\begin{array}{c}0.02 \\
{[0.02]}\end{array}$ \\
\hline & $\mathrm{N}$ & 496 & 496 & 496 & 496 & 496 & 496 & 496 \\
\hline & Mean, cont. grp. & 0.211 & 0.0523 & 0.0911 & 0.0775 & 0.0659 & 0.0329 & 0.0814 \\
\hline
\end{tabular}

$* * * \mathrm{p}<0.01, * * \mathrm{p}<0.05, * \mathrm{p}<0.1$

Note: Robust standard errors in brackets. All dependent variables are indicator variables. See Table 3 for other notes. 
Table 7: Impact of Treatment on Perceived Yields on Plots using Input Package

\author{
Dependent variable: Expected maize yield, Expected maize yield, Returns to input \\ without input package with input package (b) package (b-a)
}

(a)

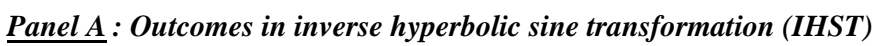

$\begin{array}{clccc}2011 & \text { Treatment } & 0.15 & 0.17^{* *} & 0.18^{*} \\ \text { season } & & {[0.10]} & {[0.083]} & {[0.097]} \\ & \mathrm{N} & 453 & 450 & 444 \\ & \text { Mean, cont. grp. } & 6.35 & 6.97 & 6.07 \\ 2012 & \text { Treatment } & 0.16 & 0.29 * * & 0.34^{* *} \\ \text { season } & & {[0.12]} & {[0.13]} & {[0.16]} \\ & \mathrm{N} & 406 & 398 & 393 \\ & \text { Mean, cont. grp. } & 6.45 & 7.06 & 6.08 \\ \text { 2013 } & \text { Treatment } & 0.080 & & 0.066 \\ \text { season } & & {[0.073]} & 0.088 & {[0.083]} \\ & \mathrm{N} & 437 & 40.067] & 434 \\ & \text { Mean, cont. grp. } & 6.39 & 7.03 & 6.13 \\ \text { Average, } & \text { Treatment } & & & 0.19^{* *} \\ \text { 2012-2013 } & & 0.12 & 0.17 * * & {[0.074]} \\ \text { seasons } & \mathrm{N} & {[0.076]} & {[0.066]} & 469 \\ & \text { Mean, cont. grp. } & 473 & 471 & 6.07\end{array}$

\title{
Panel B: Outcomes in levels
}

$\begin{array}{clccc}2011 & \text { Treatment } & 154 & 214 & 73.6 \\ \text { season } & & {[139]} & {[184]} & {[84.5]} \\ & \mathrm{N} & 453 & 450 & 444 \\ & \text { Mean, cont. grp. } & 917 & 1633 & 745 \\ 2012 & \text { Treatment } & 347^{* *} & & \\ \text { season } & & {[151]} & 659 * & 168 \\ & \mathrm{~N} & 406 & {[361]} & {[192]} \\ & \text { Mean, cont. grp. } & 1062 & 398 & 393 \\ & & & 1938 & 922 \\ 2013 & \text { Treatment } & 50.8 & & -18.3 \\ \text { season } & & {[67.0]} & 57.5 & {[92.2]} \\ & \mathrm{N} & 437 & 4139] & 434 \\ & \text { Mean, cont. grp. } & 982 & 1920 & 919 \\ \text { Average, } & \text { Treatment } & & & 88.5 \\ \text { 2012-2013 } & & 202^{* *} & 352^{*} & {[93.9]} \\ \text { seasons } & \mathrm{N} & {[86.4]} & {[191]} & 469 \\ & \text { Mean, cont. grp. } & 473 & 471 & 881\end{array}$

*** $\mathrm{p}<0.01,{ }^{* *} \mathrm{p}<0.05,{ }^{*} \mathrm{p}<0.1$

Note: Robust standard errors in brackets. Yield expressed as kilograms of maize per hectare. Respondent asked to assume use of $100 \mathrm{~kg}$ of NPK fertilizer, $100 \mathrm{~kg}$ of urea fertilizer, and $25 \mathrm{~kg}$ of improved seeds per hectare. See Table 3 for other notes. 
Table 8: Social network statistics

A. Size of social network

\begin{tabular}{crr} 
& Count & Share \\
0 & 154 & $30.0 \%$ \\
1 & 83 & $16.1 \%$ \\
2 & 65 & $12.6 \%$ \\
3 & 38 & $7.4 \%$ \\
4 & 44 & $8.6 \%$ \\
5 & 26 & $5.1 \%$ \\
6 & 18 & $3.5 \%$ \\
7 & 16 & $3.1 \%$ \\
8 & 17 & $3.3 \%$ \\
9 & 10 & $1.9 \%$ \\
10 & 11 & $2.1 \%$ \\
11 & 10 & $1.9 \%$ \\
12 & 6 & $1.2 \%$ \\
13 or more & 16 & $3.1 \%$ \\
& & \\
\hline Total & &
\end{tabular}

Addendum:

5 or more $\underline{\text { B. Number of voucher winners in social network }}$

\begin{tabular}{crr} 
& Count & Share \\
0 & 226 & $44.0 \%$ \\
1 & 94 & $18.3 \%$ \\
2 & 77 & $15.0 \%$ \\
3 & 42 & $8.2 \%$ \\
4 & 30 & $5.8 \%$ \\
5 & 17 & $3.3 \%$ \\
6 & 12 & $2.3 \%$ \\
7 & 5 & $1.0 \%$ \\
8 & 4 & $0.8 \%$ \\
9 & 1 & $0.2 \%$ \\
10 & 4 & $0.8 \%$ \\
11 & 0 & $0.0 \%$ \\
12 & 0 & $0.0 \%$ \\
13 or more & 2 & $0.4 \%$ \\
\hline Total & & \\
\hline
\end{tabular}

Addendum:

5 or more

45

$8.8 \%$

Note: Social network size defined as number of study participants in the same village with whom respondent talked about agriculture in the previous season (2009-2010) at "moderately" or "a lot" (as opposed to "a bit" or not at all). Respondents asked on average about social network links to 11.5 other individuals in their village. 


\section{Table 9: Treatment spillovers in social network}

Dependent variable:

Fertilizer used (inverse hyperbolic sine transformation)

$$
2011 \text { season } 2012 \text { season } 2013 \text { season } \begin{gathered}
\text { Average, } 2012- \\
13 \text { seasons }
\end{gathered}
$$

\section{Panel A : Fertilizer on maize}

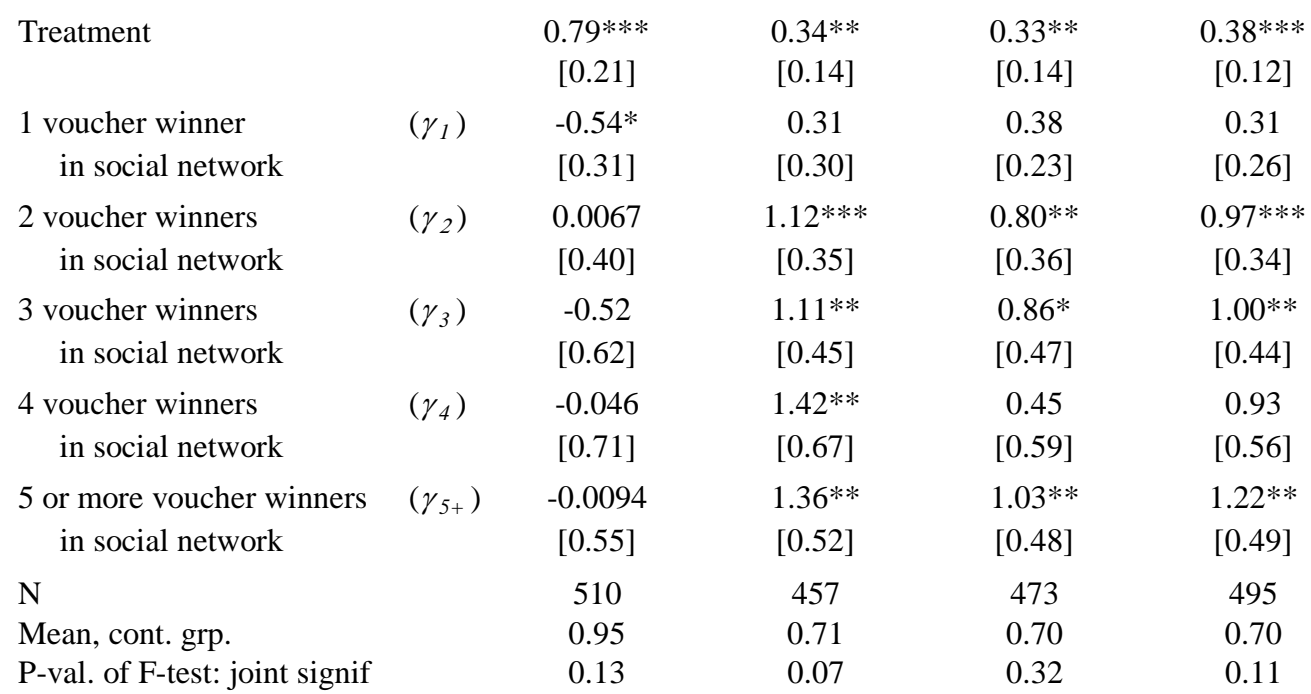

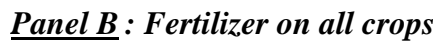

$\begin{array}{lccccc}\text { Treatment } & & 0.60^{* *} & 0.47 * * * & 0.33^{*} & 0.50^{* * *} \\ & & {[0.24]} & {[0.17]} & {[0.18]} & {[0.16]} \\ 1 \text { voucher winner } & \left(\gamma_{1}\right) & -0.35 & 0.41 & 0.72 * * & 0.52^{*} \\ \quad \text { in social network } & & {[0.29]} & {[0.34]} & {[0.27]} & {[0.29]} \\ 2 \text { voucher winners } & \left(\gamma_{2}\right) & -0.27 & 0.65 & 1.04^{* * *} & 0.86^{* * *} \\ \quad \text { in social network } & & {[0.47]} & {[0.51]} & {[0.24]} & {[0.31]} \\ 3 \text { voucher winners } & \left(\gamma_{3}\right) & -0.77 & 1.09 & 1.12^{*} & 1.14^{* *} \\ \quad \text { in social network } & & {[0.63]} & {[0.70]} & {[0.60]} & {[0.55]} \\ 4 \text { voucher winners } & \left(\gamma_{4}\right) & -1.03 & 0.62 & 1.18^{*} & 0.93^{* *} \\ \quad \text { in social network } & & {[0.63]} & {[0.69]} & {[0.60]} & {[0.46]} \\ 5 \text { or more voucher winners } & \left(\gamma_{5+}\right) & -1.01^{*} & 1.00 & 1.76^{* * *} & 1.37^{* * *} \\ \quad \text { in social network } & & {[0.60]} & {[0.60]} & {[0.31]} & {[0.38]} \\ \mathrm{N} \quad & & 503 & 452 & 470 & 495 \\ \text { Mean, cont. grp. } & & 1.82 & 1.37 & 1.44 & 1.37 \\ \text { P-val. of F-test: joint signif } & & 0.48 & 0.25 & 0.00 & 0.02 \\ \quad \text { of all } \gamma_{k} \text { coefficients } & & & & & \end{array}$

Note: Robust standard errors in brackets. All dependent variables expressed in inverse hyperbolic sine transformation (IHST). Regressions also include as controls indicator variables for having 1, 2, 3, 4, and "5 or more" study participants in one's social network (the category "0"is omitted). See Table 8 for social network definitions and statistics, and Table 3 for other notes on regression specification. 


\section{ONLINE APPENDIX FOR "Subsidies and the Persistence of Technology Adoption: Field Experimental Evidence from Mozambique"}

\section{Appendix: Higher Order Learning}

- Diffuse Priors: We further assume that individuals at time 0 may not only have biased beliefs, but they may also have relatively uninformed or diffuse priors about the distribution of returns. Specifically, we assume that the probability structure for an individual with unbiased beliefs $B_{0}=0$ can be written as $\phi_{\tilde{y}}\left(\tilde{y} \mid B_{0}=0\right)=\phi_{y}(y)+m_{0}(y)$ where $m_{0}(y)$ is a mean preserving spread defined such that:

$$
\int m_{0}(y) d y, \int m_{0}(y) \phi_{y}(y) d y=0
$$

and that

$$
\left.\int\left[\Phi_{\tilde{y}}(y)\right)-\Phi_{y}(\tilde{y})\right] \geq 0 \forall y \leq y^{+}
$$

where $\Phi_{i}$ denotes the cumulative distribution function corresponding to random variable $i$. More generally, $\phi_{\tilde{y}}\left(\tilde{y} \mid B_{0}\right)=\phi_{y}\left(y+B_{0}\right)+m_{0}\left(y+B_{0}\right)$. For the special case in which priors are not diffuse, but are potentially biased, we can write $\phi_{\tilde{y}}(\tilde{y})=\phi_{y}\left(y+B_{0}\right)$.

- Distribution of Returns: Second, we assume that learning reduces the diffuseness of prior beliefs. In particular, we assume that based on observation of own and neighbors' period 1 returns to fertilizers, updated period 1 beliefs are no more diffuse than period 1 beliefs. Specifically, holding the bias in expected returns constant, period 0 beliefs can always be expressed as a mean preserving spread of period 1 beliefs. 
While there are various ways to model learning, we here assume that learning is naive or unanticipated. Under this assumption, first period choice is exactly as modeled above. However, unanticipated learning will make second period or sustained adoption more likely under our assumption that experience operates as a mean preserving squeeze, making $\phi^{1}(y)$ less diffuse than the prior $\phi^{0}(y)$. As shown above, this shift in subjective beliefs will lower $\tilde{z}_{2}$, making expanding the set of individuals who will sustain adoption of the new technology. 
